\title{
Habitability of the Phoenix landing site
}

\author{
Carol R. Stoker, ${ }^{1}$ Aaron Zent, ${ }^{1}$ David C. Catling, ${ }^{2}$ Susanne Douglas, ${ }^{3}$ John R. Marshall, ${ }^{4}$
} Douglas Archer Jr., ${ }^{5}$ Benton Clark, ${ }^{6}$ Samuel P. Kounaves, ${ }^{7}$ Mark T. Lemmon, ${ }^{8}$ Richard Quinn, ${ }^{4}$ Nilton Renno, ${ }^{9}$ Peter H. Smith, ${ }^{5}$ and Suzanne M.M. Young ${ }^{10}$

Received 6 May 2009; revised 11 December 2009; accepted 7 January 2010; published 16 June 2010.

[1] The Phoenix mission's key objective was to search for a habitable zone. Mission results are used to evaluate habitability where Phoenix landed. A habitability probability $(H I)$ is defined as the product of probabilities for the presence of liquid water $\left(P_{l w}\right)$, energy $\left(P_{e}\right)$, nutrients $\left(P_{c h}\right)$, and a benign environment $\left(P_{b}\right)$. Observational evidence for the presence of liquid water (past or present) includes clean ice at a polygon boundary, chemical etching of soil grains, and carbonate minerals. The presence of surface and near subsurface ice, along with thermodynamic conditions that support melting, suggest that liquid water is theoretically possible. Presently, unfrozen water can form only in adsorbed films or saline brines but more clement conditions recur periodically due to variations in orbital parameters. Energy to drive metabolism is available from sunlight, when semitransparent soil grains provide shielding from UV radiation and chemical energy from the redox couple of perchlorate and reduced iron. Nutrient sources including C, H, N, O, P, and $\mathrm{S}$ compounds are supplied by known atmospheric sources or global dust.

Environmental conditions are within growth tolerance for terrestrial microbes. Surface soil temperatures currently reach $260 \mathrm{~K}$ and are periodically much higher, the $\mathrm{pH}$ is 7.8 and is well buffered, and the water activity is high enough to allow growth when sufficient water is available. Computation of $H I$ for the sites visited by landers yields Phoenix, 0.47; Meridiani, 0.23; Gusev, 0.22; Pathfinder, 0.05; Viking 1, 0.01; Viking 2, 0.07. HI for the Phoenix site is the largest of any site explored, but dissimilar measurements limit the comparisons' confidence.

Citation: Stoker, C. R., et al. (2010), Habitability of the Phoenix landing site, J. Geophys. Res., 115, E00E20, doi:10.1029/2009JE003421.

\section{Introduction and Background}

[2] The unifying goal of the Mars Exploration program, as laid out in the roadmap of NASA's Mars Exploration Payload Analysis Group (MEPAG), is the search for life on Mars [Beaty et al., 2006] (see also http://mepag.jpl.nasa. gov/reports/index.html). However, experience from the

\footnotetext{
${ }^{1}$ NASA Ames Research Center, Moffett Field, California, USA.

${ }^{2}$ Department of Earth and Space Sciences and Astrobiology Program, University of Washington, Seattle, Washington, USA.

${ }^{3}$ Jet Propulsion Laboratory, Pasadena, California, USA.

${ }^{4}$ SETI Institute, Mountain View, California, USA.

${ }^{5}$ Lunar and Planetary Laboratory, University of Arizona, Tucson, Arizona, USA.

${ }^{6}$ Space Science Institute, Boulder, Colorado, USA. USA.

${ }^{7}$ Department of Chemistry, Tufts University, Medford, Massachusetts,

${ }^{8}$ Department of Atmospheric Sciences, Texas A\&M University, College Station, Texas, USA.

${ }^{9}$ Department of Atmospheric, Oceanic, and Space Sciences, University of Michigan, Ann Arbor, Michigan, USA.

${ }^{10}$ Department of Chemistry, University of New Hampshire, Durham, New Hampshire, USA.

Copyright 2010 by the American Geophysical Union. 0148-0227/10/2009JE003421
}

Viking Landers clearly shows that this goal is difficult to achieve without characterizing the physical and chemical environment [Klein, 1978] and thus the approach recommended is first to identify habitable environments prior to conducting a mission to search for life. The Phoenix mission is the first NASA Mars Scout mission led by a principal investigator (Peter Smith) and competitively selected through peer review. It is also the first mission launched with the objective of assessing the habitability of the Martian environment. The mission was designed to land in Mars' far northern hemisphere where near surface ground ice had been identified based on data from orbiting neutron detectors on the Gamma Ray Spectrometer (GRS) carried by Mars Odyssey [Boynton et al., 2002; Feldman et al., 2002; Mitrofanov et al., 2002]. The area was considered important for study because of the possible periodic presence of liquid water as orbital dynamics change the regional climate. The two primary mission objectives to be achieved at the landing site were (1) study the history of water in all its phases and (2) search for habitable zones [Smith, 2002; Smith et al., 2008]. A habitable zone, by definition, is capable of supporting living organisms with capabilities similar to terrestrial microbes. One of the major requirements for life is the 

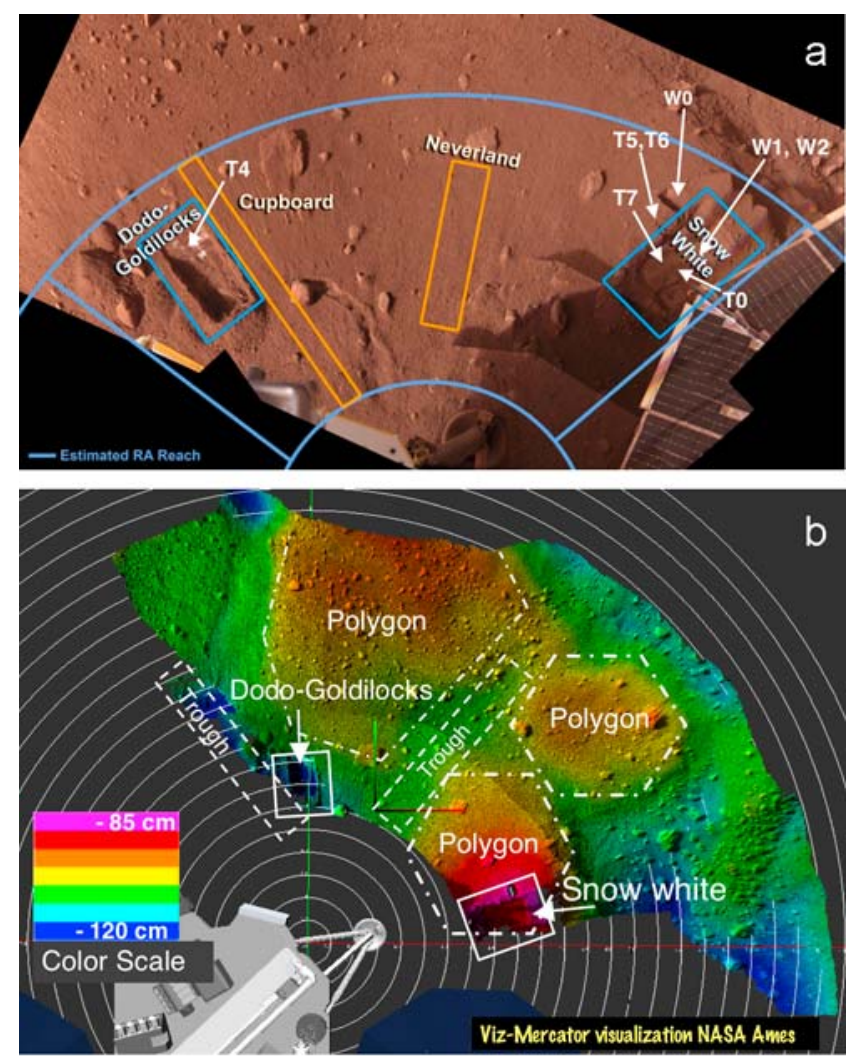

Figure 1. (a) Diagram of the work area accessible by the Phoenix Lander's arm (blue outline) superimposed on an image mosaic acquired by the SSI camera. The boxed areas are sites where trenches were dug for sample collection and exploration of subsurface material. Arrows point to locations where samples were acquired that were analyzed by either WCL (cells $0,1,2$ ) denoted as W0-W2 or TEGA (ovens designated T0-T7). The arm's maximum reach is approximately $1.5 \mathrm{~m}$. (b) Viz-Mercator visualization of the arm work area. The data are displayed as a color-coded elevation model. A graphic model of the lander is at the bottom left. Radial grid lines spaced $20 \mathrm{~cm}$ apart are centered on the robotic arm shoulder rotation axis. The color scale is shown at left. Dark blue represents the lowest regions which are $120 \mathrm{~cm}$ below the lander deck. The highest regions (pink) are $35 \mathrm{~cm}$ higher. White dotted lines illustrate approximate polygon boundaries. Dashed lines demark the position of troughs. White boxes show the two trenches Dodo Goldilocks and Snow White.

presence of liquid water and the northern region of Mars, with its water ice cap and shallow subsurface ice, promised to provide the greatest likelihood for achieving both of the primary mission objectives.

[3] Given that the Phoenix mission site selection and payload were designed to gain an understanding of the habitability of the environment, we describe the physical and chemical aspects of the Phoenix landing site and relate them to habitability. We also endeavor to make this evaluation more meaningful by establishing quantitative criteria to assess the habitability of the landing site through a "habitability index," described below, which we apply not only to the Phoenix site but to other landing sites as well.
The index allows a relative habitability assessment based on a wide range of in situ observations made on Mars.

\section{Mission Approach and Payload}

[4] The Phoenix mission launched on 4 August 2007 and landed on 25 May 2008 at the northern polar location of $68.22^{\circ} \mathrm{N}, 234.25^{\circ} \mathrm{E}$ (areocentric) and elevation of $-4.1 \mathrm{~km}$ (referenced to Mars Orbiter Laser Altimeter topography). The regional area of the landing site was on the Scandia Formation, a plains deposit composed of fine-grained material ranging from 20 to $200 \mathrm{~m}$ thick that overlies the Vastitas Borealis formation between Alba Patera and Olympia Planitia [Tanaka et al., 2005]. The entire regional area where the spacecraft landed was covered with patterned ground, a common feature of periglacial terrain. Around the landing site this manifests as small-scale polygon features only a few meters in typical size [Mellon et al., 2009]. Fortuitously, both a polygon center and trough areas separating polygons could be accessed with the robotic arm (Figure 1a).

[5] The process for selecting the landing site is reviewed by Arvidson et al. [2008]. A driving consideration was to find a location where water ice could be accessed within the digging depth capability of the robotic arm, a maximum of $50 \mathrm{~cm}$. Detailed consideration of the GRS data from the north polar region, images from the High Resolution Imaging Science Experiment (HiRISE) on Mars Reconnaissance Orbiter (MRO), as well as other studies, identified a landing site with the desired characteristics of near surface ground ice and low rock abundance. The average dry soil abundance over the icy surface, predicted by modeling the Odyssey GRS data for the landing site area, was $10 \mathrm{~g} / \mathrm{cc}$ (5 cm soil depth) [Arvidson et al., 2008]. The observed ice table depth at the landing site was in good agreement with this prediction.

[6] The Phoenix payload elements have been described by Smith et al. [2008]. Each instrument was relevant for determining habitability. The Surface Stereo Imager (SSI), a multispectral stereo imaging system, was used to identify visual evidence of a history of liquid water. Samples were collected using a robotic arm with a scoop equipped with a scraping blade and a small drilling device, called the Icy Soil Acquisition Device (ISAD) [Bonitz et al., 2008] that could penetrate into hard icy material and direct cuttings into the scoop. The Robotic Arm Camera (RAC) [Keller et al., 2008] could image the contents of the scoop at a resolution up to 24 microns per pixel. Collected samples were placed in analytical instruments including the Thermal Evolved Gas Analyzer (TEGA) [Boynton et al., 2009] and the package of instruments called the Microscopy, Electrochemistry, and Conductivity Analyzer (MECA) [Hecht et al., 2008, 2009; Kounaves et al., 2009; Zent et al., 2009, 2010]. TEGA's capabilities related to habitability assessment included detection and quantification of organic compounds [Boynton et al., 2009; Ming et al., 2008] and of minerals formed in an aqueous environment. TEGA could also determine the isotopic composition of carbon, important for habitability because microbial processing isotopically fractionates carbon.

[7] The MECA instrument package included a 4 micron/ pixel resolution color optical microscope (OM) [Hecht et 
Table 1. Samples Analyzed by TEGA and WCL Instruments

\begin{tabular}{|c|c|c|c|c|}
\hline Instrument & Sol & Trench & Sample Name & Type of Sample \\
\hline MECA WCL-0 & 30 & Burn Alive & Rosy Red_Sol25 & Loose soil above ice-cemented soil at polygon center, $1 \mathrm{~cm}$ depth \\
\hline MECA WCL-1 & 41 & Sorceress & Sorceress & Soil scraped from ice-cemented soil at polygon center, $5 \mathrm{~cm}$ depth \\
\hline MECA WCL-3 & 96 & Stone Soup & Golden Goose & Loose cloddy soil in polygon trough area, $15 \mathrm{~cm}$ depth \\
\hline MECA WCL-2 & 107 & Snow White & Sorceress 2 & Soil scraped from ice-cemented soil at polygon center, $5 \mathrm{~cm}$ depth \\
\hline TEGA-4 & 12 & Goldilocks & Baby Bear & $\begin{array}{l}\text { Loose surface soil above nearly pure ice, } 1 \mathrm{~cm} \text { depth (*Perchlorate found, } \\
\left.\text { probably as } \mathrm{Mg}, \mathrm{Ca} \text {, or } \mathrm{Na}\left(\mathrm{ClO}_{4}\right)_{2}\right)\end{array}$ \\
\hline TEGA-0 & 64 & Snow White & Wicked Witch & Sample scraped from ice cemented soil in polygon center, $5 \mathrm{~cm}$ depth \\
\hline TEGA-5 & 72 & Rosy Red3 & Rosy Red_Sol72 & Loose soil at surface from polygon center, $1 \mathrm{~cm}$ depth \\
\hline TEGA-7 & 85 & Burn Alive & Burning Coals & $\begin{array}{l}\text { Sample from mid depth in loose soil above ice cemented soil in polygon } \\
\text { center, depth } 3-4 \mathrm{~cm}\end{array}$ \\
\hline TEGA-1 & 130 & $\mathrm{n} / \mathrm{a}$ & $\mathrm{n} / \mathrm{a}$ & No sample in oven, run as a blank \\
\hline TEGA-6 & 136 & Rosy Red3 & Rosy Red_Sol136 & Loose soil at surface from polygon center, $1 \mathrm{~cm}$ depth \\
\hline TEGA-3 & 151 & $\mathrm{n} / \mathrm{a}$ & $\mathrm{n} / \mathrm{a}$ & No sample in oven, run as a blank \\
\hline
\end{tabular}

al., 2008] and an atomic force microscope (AFM) capable of resolving $100 \mathrm{~nm}$. These instruments allowed soil particles to be examined for evidence of chemical etching. Soil chemistry was analyzed by the Wet Chemistry Laboratory (WCL) using four single-use cells equipped with sensors to measure $\mathrm{pH}$, Eh, conductivity, and dissolved ionic species via ion selective electrodes (ISE) for $\mathrm{Na}^{+}, \mathrm{K}^{+}, \mathrm{Mg}^{2+}, \mathrm{Ca}^{2+}$, $\mathrm{Ba}^{2+}, \mathrm{NH}_{4}^{+}, \mathrm{Cl}^{-}, \mathrm{Br}^{-}, \mathrm{I}^{-}$, and $\mathrm{NO}_{3}^{-} / \mathrm{ClO}_{4}^{-}$as well as electrodes performing cyclic voltammetry and chronopotentiometry [Kounaves et al., 2009]. The WCL was able to identify soluble ions useful as growth resources, in addition to assessing whether the chemical environment was conducive to biology. The Thermal and Electrical Conductivity Probe (TECP) [Zent et al., 2009] was inserted into the soil to measure temperature, relative humidity, and other thermophysical and electrical properties related to the amount of unfrozen water present in the soil. Aerial measurements with the TECP were used to determine the relative humidity in the atmosphere, useful for assessing surface-atmosphere $\mathrm{H}_{2} \mathrm{O}$ exchange. Since water is central to life, information about the distribution of water was important for the habitability assessment. Finally, the meteorological package, (MET) [Whiteway et al., 2008] measured atmospheric temperature and pressure in addition to a dual wavelength lidar that permitted measurement of cloud particle vertical distribution and density [Whiteway et al., 2009].

[8] For 152 sols Phoenix excavated the surface, collected and analyzed soils and icy materials, and made extensive atmospheric measurements. Arvidson et al. [2009] summarizes the samples collected throughout the mission. The arm work area and locations of the main trenches are shown in Figure 1a. Figure 1b shows the topography of the arm work area, including polygons and the surrounding troughs. The trench at the far left of the work area was called Dodo Goldilocks (DG) and was dug in a topographically low area sloping to the southwest along the edge of a polygon and grading into a trough between polygons (Figure 1b). A hard bright layer was encountered at $3 \mathrm{~cm}$ depth. The trench at the far right of the work area was called Snow White (SW) and was dug in the center of a polygon in a higher flat-lying area. The hard layer reached at $5 \mathrm{~cm}$ depth was soil colored. Table 1 lists the samples delivered to the TEGA and WCL instruments, and sample locations are shown in Figure 1a. One surface sample came from the DG trench. Deeper trenching revealed pure ice at the trench bottom, but this was not sampled. The rest of the samples came from the SW trench and were either loose soil or were scraped from the soil-ice interface.

\section{Habitability Assessment Approach}

[9] Much has been written about the habitability of various locations on Mars, primarily based on evidence for liquid water regardless of when it occurred. Before missions to search for life can be justified, a more quantitative approach to assessing habitability is needed that will allow a comparison between the locations visited. For this reason, we present a formulaic approach for producing a quantitative evaluation of the habitability of a landing site and apply the assessment to the Phoenix site. The approach derives its inspiration from the famous "Drake equation" [e.g., Drake and Sobel, 1992] and follows a recommendation from the Mars Exploration Payload Analysis Group (MEPAG) Astrobiology Field Laboratory Science Working Group (available at http://mepag.jpl.nasa.gov/reports/index.html). Beaty et al. [2006] used similar arguments to identify "special regions" on Mars where growth is possible.

[10] Given our current understanding of life, the potential for habitability in a specific time and space encompasses three probabilities that take values from 0 to 1 . These are (1) the presence of liquid water $\left(P_{l w}\right),(2)$ the presence of a biologically available energy source $\left(P_{e}\right)$, and (3) the presence of elements essential to life as we know it (e.g., C, H, $\mathrm{N}, \mathrm{O}, \mathrm{P}, \mathrm{S})$ in a biologically available form $\left(P_{c h}\right)$. In addition to these probabilistic factors, temperature and water activity must also be high enough to support growth, and the environmental conditions must not be too extreme or toxic to allow life. Since the relevant factors allowing life must be simultaneously present, MEPAG suggested the use of a habitability index, defined as follows:

$$
H I_{\mathrm{MEPAG}}=P_{l w} P_{e} P_{c h}
$$

MEPAG posited that a life detection mission could not be justified unless a previous mission had determined $H I_{\text {MEPAG }}$ to have a combined probability greater than 0.5 . We note that a $H I_{\mathrm{MEPAG}}$ of 0.5 demands high values for the component probabilities $P_{l w}, P_{e}$, and $P_{c h}$, since $(0.8)^{1 / 3}=0.5$. In 
Table 2. Probabilities, Factors, and Weights Considered in the Calculation of a Habitability Index ${ }^{\mathrm{a}}$

\begin{tabular}{|c|c|c|c|c|c|c|}
\hline & Liquid Water, $P_{l w}$ & Energy, $P_{e}$ & CHNOPS, $P_{c h}$ & $\begin{array}{c}\text { Benign } \\
\text { Environment, } \\
P_{b}\end{array}$ & $H I$ & $H I_{\text {MEPAG }}$ \\
\hline \multirow[t]{4}{*}{ Factors considered } & $\begin{array}{l}F_{o b s}, \text { observational, } \\
\text { based on weighted } \\
\text { sum of factors with } \\
\text { uniform weights }\end{array}$ & $\begin{array}{l}F_{e 1}-\text { surface } \\
\text { UV-shielded } \\
\text { photosynthetically } \\
\text { active radiation } \\
\text { available }\end{array}$ & $\begin{array}{l}F_{C}, F_{H}, F_{N}, F_{O}, \\
\quad F_{P}, F_{S}\end{array}$ & $\begin{array}{l}F_{T} \text {-temperature } \\
\text { in growth range }\end{array}$ & & \\
\hline & $\begin{array}{c}F_{o b s 1}, F_{o b s 2}, F_{o b s 3} \\
F_{o b s 4}(\text { see text })\end{array}$ & $\begin{array}{l}F_{e 2}-\text { redox pair } \\
\text { for metabolism } \\
\text { available }\end{array}$ & $\begin{array}{l}\text { Each factor } \\
\text { represents the } \\
\text { presence of } \\
\text { CHNOPS } \\
\text { compounds }\end{array}$ & $\begin{array}{c}F a_{\mathrm{w}} \text {-water activity } \\
\text { allows growth }\end{array}$ & & \\
\hline & $\begin{array}{l}F_{\text {th }}-\text { theoretical } \\
\text { based on } \\
\text { multiplying } \\
\text { factors }\end{array}$ & & & $F_{p H},-$ benign $\mathrm{pH}$ & & \\
\hline & $F_{t h 1}, F_{t h 2}, F_{t h 3}($ see text $)$ & & & $\begin{array}{c}F_{\text {org }}-\text { presence of } \\
\text { organics }\end{array}$ & & \\
\hline Weights & $W_{o b s}=1, W_{t h}=0.5$ & $W_{e 1}=1, W_{e 2}=0.5$ & Uniform & Uniform & & \\
\hline Phoenix factors & $\begin{array}{l}F_{o b s 1}=0.5 \\
F_{o b s 2}=0.5 \\
F_{o b s 3}=0.5 \\
F_{o b s 4}=1 \\
\text { Total } F_{o b s}=0.63 \\
F_{t h}=1 * 1 * 0.5\end{array}$ & $\begin{array}{l}F_{e 1}=1 \\
F_{e 2}=1\end{array}$ & $\begin{array}{l}F_{C}=1 \\
F_{H}=1 \\
F_{N}=0.5 \\
F_{O}=1 \\
F_{P}=1 \\
F_{S}=1\end{array}$ & $\begin{array}{l}F_{T}=1 \\
F a_{\mathrm{w}}=1 \\
F_{p H}=1 \\
F_{\text {org }}=0.25\end{array}$ & & \\
\hline$P_{n}$ Phoenix & 0.58 & 1.0 & 0.92 & 0.81 & 0.43 & 0.53 \\
\hline Meridiani factors & $\begin{array}{l}F_{o b s 1}=1 \\
F_{o b s 2}=1 \\
F_{o b s 3}=1 \\
F_{o b s 4}=\mathrm{NA} \\
\text { Total } F_{\text {obs }}=1.0 \\
F_{t h}=1 * 1 * 1\end{array}$ & $\begin{array}{l}F_{e 1}=0.5 \\
F_{e 2}=0.5\end{array}$ & $\begin{array}{l}F_{C}=1 \\
F_{H}=1 \\
F_{N}=0.5 \\
F_{O}=1 \\
F_{P}=1 \\
F_{S}=1\end{array}$ & $\begin{array}{l}F_{T}=1 \\
F_{p H}=0.25 \\
F a_{\mathrm{w}}=0.25 \\
F_{\text {org }}=\text { NA }\end{array}$ & & \\
\hline $\mathrm{P}_{\mathrm{n}}$ Meridiani & 1.0 & 0.5 & 0.92 & 0.5 & 0.23 & 0.46 \\
\hline Gusev factors & $\begin{array}{l}F_{o b s 1}=1 \\
F_{o b s 2}=0 \\
F_{o b s 3}=1 \\
F_{o b s 4}=\text { NA } \\
\text { Total } F_{o b s}=0.67 \\
F_{t h}=1 * 1 * 1\end{array}$ & $\begin{array}{l}F_{e 1}=0.5 \\
F_{e 2}=0.5\end{array}$ & $\begin{array}{l}F_{C}=1 \\
F_{H}=1 \\
F_{N}=0.5 \\
F_{O}=1 \\
F_{P}=1 \\
F_{S}=1\end{array}$ & $\begin{array}{l}F_{T}=0.75 \\
F a_{\mathrm{w}}=0.5 \\
F_{p H}, F_{\text {org }}=\mathrm{NA}\end{array}$ & & \\
\hline$P_{n}$ Gusev & 0.78 & 0.5 & 0.92 & 0.63 & 0.22 & 0.36 \\
\hline Pathfinder factors & $\begin{array}{l}F_{o b s 1}=0.25 \\
F_{o b s 2}=\mathrm{NA} \\
F_{o b s 3}=\mathrm{NA} \\
F_{o b s 4}=\mathrm{NA} \\
\text { Total } F_{o b s}=0.25 \\
F_{t h}=1 * 0.25 * 0.5\end{array}$ & $\begin{array}{l}F_{e 1}=0.5 \\
F_{e 2}=0.5\end{array}$ & $\begin{array}{l}F_{C}=1 \\
F_{H}=1 \\
F_{N}=0.5 \\
F_{O}=1 \\
F_{P}=1 \\
F_{S}=1\end{array}$ & $\begin{array}{l}F_{T}=0.5 \\
F a_{\mathrm{w}}=0.5 \\
F_{p H}, F_{\text {org }}=\mathrm{NA}\end{array}$ & & \\
\hline$P_{n}$ Pathfinder & 0.21 & 0.5 & 0.92 & 0.5 & 0.05 & 0.10 \\
\hline VL 1 factors & $\begin{array}{l}F_{o b s 1}=0 \\
F_{o b s 2}=\mathrm{NA} \\
F_{o b s 3}=\mathrm{NA} \\
F_{o b s 4}=\mathrm{NA} \\
\text { Total } F_{o b s}=0 \\
F_{t h}=1 * 0.25 * 0.5\end{array}$ & $\begin{array}{l}F_{e 1}=0.5 \\
F_{e 2}=0.5\end{array}$ & $\begin{array}{l}F_{C}=1 \\
F_{H}=1 \\
F_{N}=0.5 \\
F_{O}=1 \\
F_{P}=1 \\
F_{S}=1\end{array}$ & $\begin{array}{l}F_{T}=0.5 \\
F_{p H}=0.75 \\
F a_{\mathrm{w}}=0.5 \\
F_{\text {org }}=0\end{array}$ & & \\
\hline$P_{n}$ VL 1 & 0.04 & 0.5 & 0.9 & 0.44 & 0.01 & 0.02 \\
\hline
\end{tabular}


Table 2. (continued)

\begin{tabular}{|c|c|c|c|c|c|c|}
\hline & Liquid Water, $P_{l w}$ & Energy, $P_{e}$ & CHNOPS, $P_{c h}$ & $\begin{array}{c}\text { Benign } \\
\text { Environment, } \\
P_{b}\end{array}$ & $H I$ & $H I_{\text {MEPAG }}$ \\
\hline VL 2 factors & $\begin{array}{l}F_{o b s 1}=0 \\
F_{o b s 2}=\mathrm{NA} \\
F_{o b s 3}=\mathrm{NA} \\
F_{o b s 4}=\mathrm{NA} \\
\text { Total } F_{o b s}=0 \\
F_{t h}=1 * 1 * 0.5\end{array}$ & $\begin{array}{l}F_{e 1}=0.5 \\
F_{e 2}=1\end{array}$ & $\begin{array}{l}F_{C}=1 \\
F_{H}=1 \\
F_{N}=0.5 \\
F_{O}=1 \\
F_{P}=1 \\
F_{S}=1\end{array}$ & $\begin{array}{l}F_{T}=1 \\
F_{p H}=0.75 \\
F a_{\mathrm{w}}=1 \\
F_{\text {org }}=0\end{array}$ & & \\
\hline$P_{n}$ VL 2 & 0.17 & 0.67 & 0.92 & 0.69 & 0.07 & 0.10 \\
\hline
\end{tabular}

${ }^{a}$ The resulting probabilities are shown. Where a factor is unknown or unmeasured "NA" indicates not applicable. Habitability Index $(H I)$ considers all four $P$ factors $\left(P_{l w}, P_{e}, P_{c h}, P_{b}\right)$ while $H I_{\text {MEGAG }}$ considers only three $P$ factors $\left(P_{l w}, P_{e}, P_{c h}\right)$.

our analysis, we expand the habitability index by adding a fourth probability: the presence of a chemically and physically benign environment $\left(P_{b}\right)$, as follows:

$$
H I=P_{l w} P_{e} P_{c h} P_{b}
$$

Each of the above probabilities can further be decomposed into $n$ contributing factors, each with values from 0 to 1 that combine for its evaluation. We compute each probability in equation (2) as a weighted mean of the $n$ contributing factors:

$$
P_{j}=\frac{\sum_{i=1}^{n} W_{i} F_{j i}}{\sum_{i=1}^{n} W_{i}}=\sum_{i=1}^{n} w_{i} F_{j i}
$$

Here $P_{j}$ are the probabilities in equation (2), where subscript $j$ is $l w, e, c h$, or $b$. Weights, $W_{i}$, estimate the relative importance and reliability of each factor, $F_{j i}$, and are also in the range 0 to 1 . Normalized weights, $w_{i}$, are given by

$$
w_{i}=\frac{W_{i}}{\sum_{i=1}^{n} W_{i}}, \quad \sum_{i=1}^{n} w_{i}=1
$$

The weighted estimate of the variance attributable to each weighed mean $P_{j}$ is then

$$
s_{P j}^{2}=\frac{1}{(n-1)} \frac{\sum_{i=1}^{n} w_{i}\left(F_{j i}-P_{j}\right)^{2}}{\sum_{i=1}^{n} w_{i}}=\frac{1}{(n-1)} \sum_{i=1}^{n} w_{i}\left(F_{j i}-P_{j}\right)^{2}
$$

The standard deviation on each $P_{j}$ is the square root of $s_{P j}^{2}$. We note that in equation (5) we are estimating a weighted variance on a weighted mean and hence the expression is divided through by $n$ compared to the variance formula for a population [e.g., Bevington, 1969, p. 73; Devore and Farnum, 1999, p. 220].

[11] Given our incomplete knowledge of Mars, the evaluation is necessarily subjective, so the factors $F_{j i}$ are assigned values of null, 0 ; low, 0.25 ; medium, 0.5 ; medium high, 0.75 ; high, 1 . The assignments are as follows: null is assigned if the factor was looked for but not observed, or no substantive theoretical arguments support the existence of the factor. Low is assigned if the factor was measured but the measurement is highly uncertain, there are numerous interpretations of the result, or the factor was not measured but weak theoretical arguments support its presence. Medium is assigned when the factor is measured but there are alternative interpretations, or the measurement is uncertain, or it is not measured but strong theoretical arguments support this factor. The value of medium high is assigned when measurements or strong theoretical arguments pertain but there is still some uncertainty. Finally, high is assigned when evidence is strong and unambiguous.

[12] Another consideration is that sometimes we may have an observation at one site on Mars but not at another, so some factors $F_{j i}$ are unknown for certain sites. For example, microscopic evidence for liquid water is unknown at the sites of Mars Pathfinder and the Viking Landers because these probes did not have microscopic imagers. When a factor is unknown it could take any value from 0 to 1 and so we do not include it, decrementing $n$ by unity in the calculation as a consequence.

[13] Making the simplifying assumption that the $P_{j}$ are independent, the overall fractional uncertainty on the habitability index, $H I$, can be calculated as

$$
\frac{s_{H I}}{H I}=\sqrt{\sum_{j=l w, e, c h, b}\left(\frac{s_{P j}}{P_{j}}\right)^{2}}
$$

Finally, we emphasize that in this estimation process we cannot generate a precise number for $H I$ because some of the input factors are only relative, given our incomplete state of knowledge from the limited nature of the measurements. Consequently, the purpose of calculating $H I$ is restricted to generating a relative comparison between different sites on Mars based on measurements from landers and, in some cases, combined with theoretical considerations.

[14] Table 2 shows the values assigned to each of the factors for Phoenix and for the other landing sites on Mars. The observations and justification of the values assigned for Phoenix are presented section 4 .

\section{Phoenix Results and Habitability Factor Assignments}

\subsection{Availability of Liquid Water}

[15] The calculation of the probability of liquid water, $P_{l w}$, relies on evaluating two metrics: (1) the observational evi- 


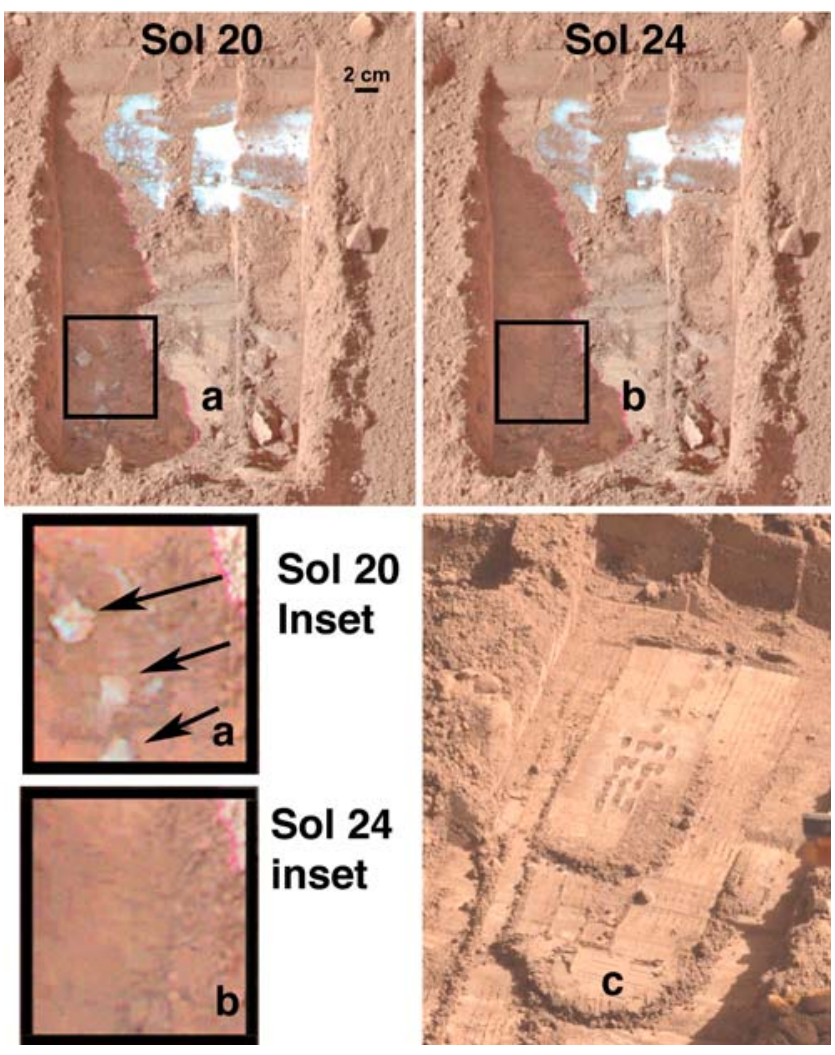

Figure 2. (a) SSI image of the Dodo Goldilocks trench showing the hard bright material in the trench floor. The boxed area contains the bright clods that broke off during digging which subsequently disappeared completely in 3 sols. (b) Same area as Figure 2a, image acquired 3 sols later than Figure 2a. (c) SSI image of the Snow White trench after excavation. The trench bottom was hard, presumably due to the presence of ice-cemented ground, but the material was spectrally identical to soil.

dence that suggests liquid water forms or has formed and (2) the theoretical considerations suggesting that liquid water can form in the environment. Next we summarize the observational evidence at the landing site that points to both the presence of water (in the form of ice) and the evidence for liquid water occurrence. The observational evidence is further subdivided into four factors: $F_{o b s}$, macroscopic morphological evidence of liquid water (for different landing sites, this factor is relative to estimated persistence or duration of the liquid water); $F_{o b s 2}$, microscopic observational evidence of liquid water; $F_{o b s 3}$, mineralogical evidence of aqueous processes; and $F_{o b s}$, evidence for thin films of unfrozen or adsorbed water measured by TECP. These factors can be combined as a weighted mean into one observational factor for liquid water, $F_{o b s}$. For the purpose of our analysis, all observational factors are weighted equally.

[16] The theoretical factor for the availability of liquid water depends on the product (or simultaneous presence) of three factors: $F_{t h 1}$, the probability of the presence of water in some form; $F_{t h 2}$, the theoretical probability that temperature and pressure conditions occur above the triple point of water; and $F_{t h 3}$, the relative duration of liquid conditions related to the stability of water in the environment when it occurred. Thus, we define the theoretical factor $F_{t h}$ as the product of these three probabilities. Finally, $P_{l w}$, our overall metric for the availability of liquid water, can be calculated as the weighted mean of $F_{o b s}$ and $F_{t h}$, where it is appropriate to give more weight to observations than theory.

\subsection{Observational Evidence for Liquid Water 4.2.1. Morphological Evidence for Pure Water Ice: Evaluating $\boldsymbol{F}_{\text {obs } 1}$}

[17] SSI imaging of the trenches revealed subsurface heterogeneity that may indicate liquid water processes. Figure 2 shows the ice exposed in the trenches at Dodo Goldilocks (Figure 2a) and Snow White (Figure 2b). The high-albedo material in DG is hard (resisting penetration by the RA scoop), localized, and has a distinct edge at the south end. It was initially covered with $3 \mathrm{~cm}$ of dry soil, so it is 2 $\mathrm{cm}$ shallower than the hard layer in the SW trench in spite of a more south facing exposure. The predicted equilibrium depth to ice for a flat-lying surface at the present time is 5 $\mathrm{cm}$ [Mellon et al., 2009]. The shallower depth to ice with more southerly exposure implies that it is out of equilibrium with the atmosphere and should be sublimating. Excavations with similar southerly slope $40 \mathrm{~cm}$ south of DG reached 18 $\mathrm{cm}$ depth without encountering hard material. Moreover, SSI multispectral observations of the DG trench indicate that the bright material is nearly pure ice. An ice absorption feature is visible in the spectra that would be completely obscured by mixing in a few percent soil [see Smith et al., 2009, Figure 2]. The ice absorption feature is not seen in SW, which is spectrally identical to soil.

[18] The DG ice may represent some variety of segregated ice. "Segregated ice" is a broad term for soil with high ice content [Davis, 2001] as opposed to pore ice that fills the interstitial space around soil particles. It is common in periglacial environments on Earth and is usually derived from liquid water. Typically, segregation occurs when a freezing front penetrates downward into fine-grained sediments and unfrozen water undergoes a phase change to ice, creating a hydraulic gradient that draws additional unfrozen water to the freezing front which then freezes to form an ice lens that displaces the overlying sediment. Relatively pure ice can also form when liquid water flows into a thermally produced crack then freezes, forming an ice wedge. Since the DG ice is located in a polygon trough, it resembles an ice wedge.

[19] There are other plausible mechanisms for emplacement of pure ice in the trough that don't involve liquid such as snow particles deposited into a thermal crack then preserved by cold temperatures and subsequently buried by soil. Snowfall was observed during the mission by the MET lidar instrument [Whiteway et al., 2009] but the clouds carry only 2 precipitable microns, so accumulating enough snow to produce the deposit in the current climate is difficult. Fisher [2005] suggested that water vapor may be directly deposited into crack or trough areas, but no terrestrial analogs are known for this process.

[20] To obtain further insight into the DG ice, it was allowed to sublimate for 90 sols until a lag deposit had formed on its surface. A sample of this lag was imaged with the MECA OM. Figure 3a shows the OM image of the DG sublimation residue compared with an OM image of a soil 

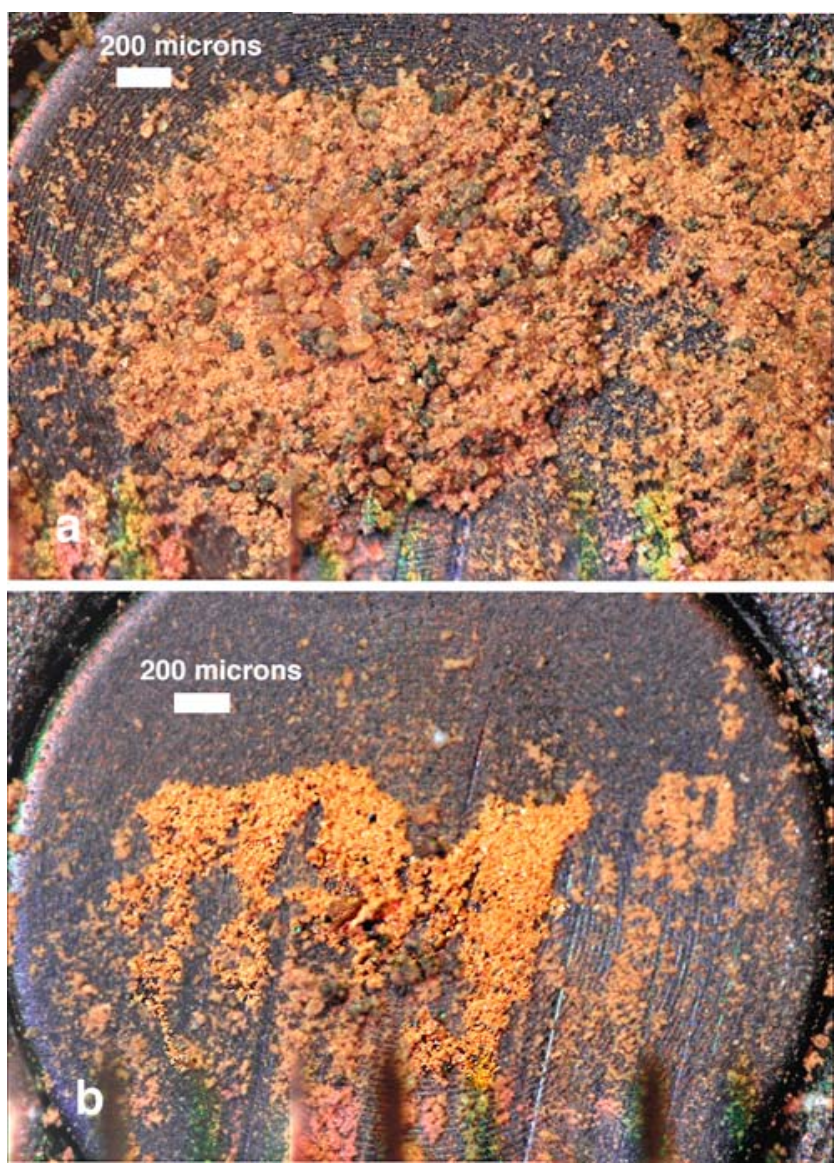

Figure 3. (a) MECA OM image of the Dodo Goldilocks sublimation residue on the strong magnet substrate, acquired on sol 99 and imaged on sol 103. This sample contained a higher fraction of silt-sized (50-150 microns) particles than did the sample scraped from Snow White. (b) MECA OM image of soil scraped from the Snow White trench on the strong magnet substrate, acquired on sol 44. There are fewer large (silt-sized) particles than in Figure 3a.

scraped from the surface of SW (Figure 3b). There are notable differences between the samples. Compared to the SW sample, the sample from DG has more particles that are silt to fine sand in size and their subrounded shape suggests wind transport. Thus, OM images of the material from DG suggest that aeolian sand was trapped in the ice when it formed. If the same process deposited the ice and sand, wind blown material would be the inferred source of the DG ice. Salts may lower the freezing point of water in Mars soils, and highly soluble freezing point depressive salts (perchlorates) were detected by WCL. Unfrozen water will concentrate salts that will be excluded when freezing occurs. The OM images of the DG lag deposit showed light-colored (but poorly resolved) small particles that are $100 \%$ more abundant than in other soils imaged [Sykulska et al., 2009], suggesting possible salt enrichment in this sample.

[21] Based on the above discussion, the term $F_{o b s 1}$ is assigned a value of medium (0.5). The observations of DG do not rule out segregated ice but other emplacement mechanisms discussed are also possible and consistent with the observations.

\subsubsection{Microscopic Evidence for Liquid Water: Evaluating $\boldsymbol{F}_{\text {obs } 2}$}

[22] The microscopic images from the MECA OM show grain surface textures and grain profiles that may be indicative of chemical dissolution, although the resolution of the images is insufficient to make definitive statements in this regard. The bulk of the silt and sand size components of the soil appear to be mechanically abraded material derived from aeolian saltation or impact (microtektites). However, some of the grains in this range of sizes appear to show evidence of selective solutional corrosion-grain surface features that are not produced by mechanical transport processes.

[23] Figure 4 shows examples of grains that have irregular outlines. These grains are silt/sand size and are characterized by irregular profiles and the presence of bulbous projections with intervening reentrants. There are a number of possible interpretations for the observed shapes with the most obvious being (1) mechanical rounding, (2) vesiculation, and (3) chemical solution. The grain shape of this minor population is not characteristic of mechanically worn grains. On Earth, mechanical (aeolian or subaqueous) attrition attacks surface protrusions on grains, and progressively encroaches

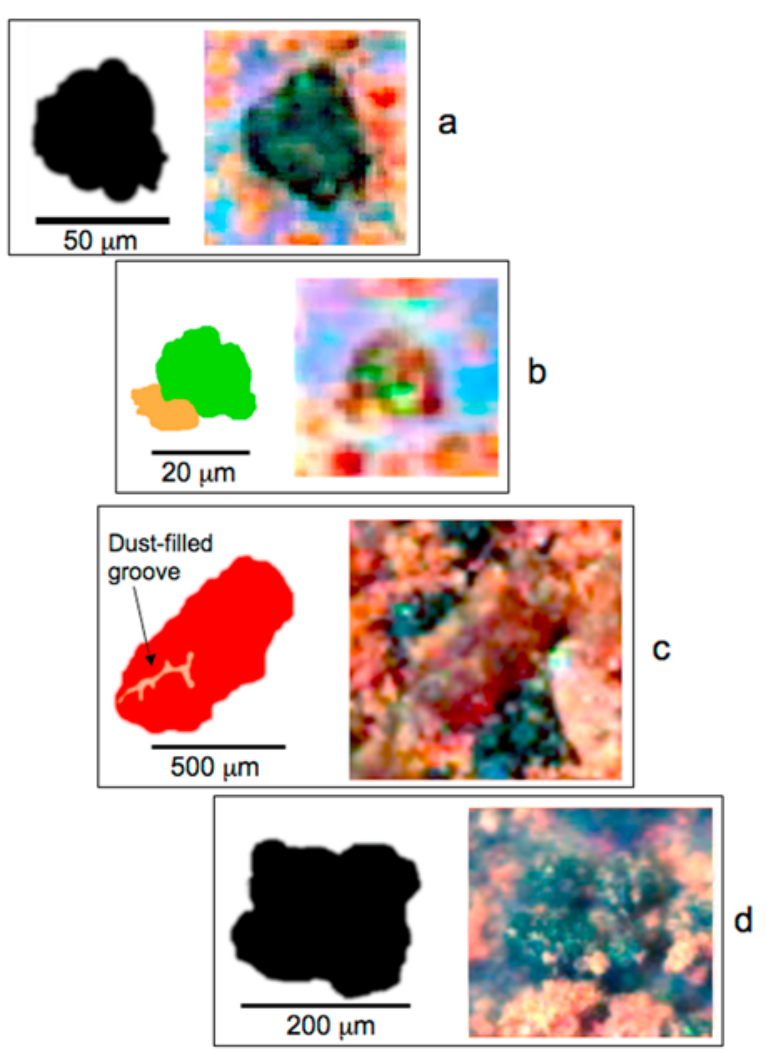

Figure 4. MECA OM images of Martian soil particles: (a) black grain with bulbous projections, (b) bright green glassy grain with "notch' or reentrant on upper side. Reentrant on lower side could be optical artifact caused by attached dust, as indicated, (c) reddish brown irregular grain with dust-filled groove as indicated, (d) black grain with grooves and central hollow. Indentations or reentrants in these grains are atypical of aeolian material and could be indications of nonmechanical weathering. 
on planar and concave surfaces. It does not lead to rounded profiles extending into surface reentrants of the type in Figure 4. The vesiculation interpretation cannot be entirely ruled out, but the grains have only vague resemblance to vesicular material (see images by Marshall [1987, pp. 46-47]) and actual vesicles cannot be identified in the images. Furthermore, vesicular material would have limited longevity in the Martian environment owing to its fragility. The third (chemical solution) interpretation is most consistent with the observations. If the observed grains are microcrystalline basalt, then each silt/sand size grain can be expected to be polycrystalline. Since the various minerals that characterize basalt have different chemical resistances, selective dissolution could lead to irregular grain shapes as is common in terrestrial (wet) environments. Krinsley [1973, pp. 67] shows examples of grains that have experienced both aeolian and chemical weathering, imaged with a Scanning Electron Microscope, that are similar to the shape, size, and morphology of the subject Phoenix grains.

[24] Unfortunately, the OM could not resolve the level of grain-surface textural detail that would be necessary for stronger conclusions to be drawn about the effects of water on surface textural evolution. Typically, this textural information starts to become visible at magnifications about twice those of the OM. Although the AFM had the theoretical resolution to define such textures, there were no occasions when the AFM could probe the surface of one of the larger sand-sized grains.

[25] Soils imaged by the OM exhibit a trimodal size distribution with a population of micron-sized particles, a population of particles that are several tens of microns in size, and a population of stones of several centimeters in size. The trimodal size distribution suggests different provenances for the soil components. The modes are consistent with a soil derived from a mixture of impact ejecta reworked by cryoturbation, tektite deposition, and aeolian transport, all mechanical processes unrelated to water. The Phoenix landing site is deflationary, and so it is also possible that some of the grains were recently exhumed from an in situ location. The micron-sized material may be aeolian material from global or regional dust storms and the ubiquitous Martian atmospheric dust. The shape of the dust is not resolved by the OM but it contains $\sim 1 \%$ of white particles that have raised speculation about the presence of salts (perchlorates in particular). However, these may be merely one of the components of windblown dust since they occur as discrete particles and not as thin layers deposited on grain surfaces as would be expected if the salts had precipitated in situ. T. Pike et al. (manuscript in preparation, 2010) posit that the size distribution characteristics of the dust imply that it was formed in a very dry environment.

[26] The factor $F_{\text {obs2 }}$ is given a value of medium based on OM images of grain shapes suggesting dissolution modification of soil grains. This interpretation is not definitive, but we believe it explains the observations better than alternative interpretations. The data provide no evidence as to whether the particles are locally derived or imported, but if the grains are saltation-transported material, they must have come from the polar region because greater distances would have destroyed the grains during transport. They must have therefore experienced a similar climate history to the Phoenix site.

\subsubsection{Mineralogical Evidence for Liquid Water: Evaluating $\boldsymbol{F}_{\text {obs } 3}$}

[27] The TEGA instrument provided mineralogical evidence for minerals produced by aqueous alteration. Lowtemperature ( $568 \mathrm{~K}$ to $1008 \mathrm{~K}$ ) water releases upon heating a surface sample from the DG area indicate the presence of hydrous minerals or phases that could include goethite, smectite, kaolinite, iron sulfates, and magnesium sulfates [Smith et al., 2009]. In samples acquired from the SW area, TEGA saw a high-temperature (between $998 \mathrm{~K}$ and $1253 \mathrm{~K}$ ) $\mathrm{CO}_{2}$ release and an accompanying endotherm in the scanning calorimetry data, interpreted as $\mathrm{CaCO}_{3}$ in the sample at a level of 3-5 wt \% [Boynton et al., 2009]. The carbonate must be of aqueous origin to be present at this high level. However, the age of the carbonate or where it formed is unknown.

[28] WCL also found evidence for carbonate species in the soil in the form of $\mathrm{pH}$, buffering capacity, and calcareous saturation. The measured $\mathrm{pH}$ of the soil/solution mixture under a headspace of carbon dioxide gave a $\mathrm{pH}$ in the range 7.7-7.9 for the samples. This $\mathrm{pH}$ suggests a carbonate buffering system, consistent with the TEGA detection of calcium carbonate in the soil [Boynton et al., 2009]. The lack of change in the $\mathrm{pH}$ on addition of an acid, which without a buffering system would have decreased the $\mathrm{pH}$ to about 3.2 , is strong indication that the sample contained a buffer system. Also, equilibrium models of the soil/solution mixture indicate that the measured ionic calcium and magnesium concentrations are most likely a product of the solution saturated in both species [Kounaves et al., 2010a].

[29] We assign the factor for aqueous mineralogy, $F_{o b s 3}$, to medium because the amount of carbonate in the soil implies it derived from aqueous weathering [Boynton et al., 2009] but the amount of carbonate is consistent with previous reports of the carbonate concentration in the global dust unit [Bandfield et al., 2003]. There is no evidence to discriminate between carbonate as a fraction of global dust or produced by local aqueous weathering.

\subsubsection{Observational Evidence for Water From TECP:} Evaluating $\boldsymbol{F}_{\text {obs } 4}$

[30] A potentially significant form of $\mathrm{H}_{2} \mathrm{O}$, from the perspective of habitability, is adsorbed water also called "thin films" or "unfrozen water." Any surface exposed to $\mathrm{H}_{2} \mathrm{O}$ vapor will accumulate $\mathrm{H}_{2} \mathrm{O}$ molecules, with abundance a function of the $\mathrm{H}_{2} \mathrm{O}$ partial pressure and the surface temperature. The current high temperatures measured by Phoenix do not preclude thin films of unfrozen water in the soil, which can exist in ice/soil systems at temperatures well below the bulk ice melting temperature [Anderson and Tice, 1972]. In frozen silty soil and clay, up to several percent of the $\mathrm{H}_{2} \mathrm{O}$ load is liquid at $253 \mathrm{~K}$ [Watanabe and Mizoguchi, 2002]. At sufficiently high abundance, the absorbed water becomes mobile in the soil. One objective of the TECP was to detect and, if possible, quantify the variations in unfrozen water throughout the mission.

[31] TECP yielded complimentary lines of evidence that $\mathrm{H}_{2} \mathrm{O}$ exchanges diurnally between the atmosphere and regolith [Zent et al., 2010]. First, the humidity sensor recorded the disappearance of $\mathrm{H}_{2} \mathrm{O}$ from the base of the atmosphere every night. As the surface and atmosphere cooled, atmospheric relative humidity $\left(\mathrm{R}_{\mathrm{H}}\right)$ increased rapidly but before either the surface or atmosphere cooled to the frost point, 


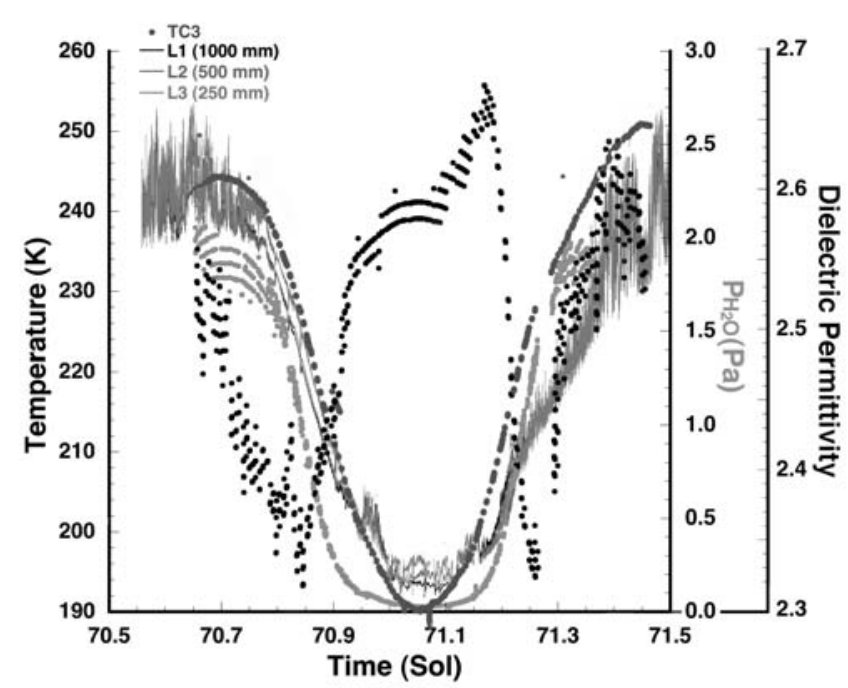

Figure 5. Regolith and atmosphere temperatures, regolith dielectric permittivity, and atmospheric $\mathrm{H}_{2} \mathrm{O}$ partial pressure for the overnight period between sols 70 and 71. Large dark gray dots (TC3) represent regolith temperatures. The light gray dots are the atmospheric water vapor pressure measured at a height of $\sim 3 \mathrm{~cm}$ above the ground surface. The black dots represent dielectric permittivity in the soil. The curves labeled L1-L3 are atmospheric temperatures from the meteorology mast.

water vapor began to disappear from the atmosphere (Figure 5). This argues for nighttime local control of atmospheric humidity through adsorption into the soil. The second line of evidence derives from the dielectric permittivity measurements that TECP made whenever it was in soil. Permittivity is very sensitive to the presence of unfrozen water. Although no evidence of unfrozen water was seen in the first half of the mission, beginning on $\operatorname{sol} 70\left(\mathrm{~L}_{\mathrm{s}}=108^{\circ}\right)$, and continuing for the rest of the mission, dielectric permittivity is inversely related to nighttime temperatures and atmospheric water vapor (Figure 5), suggesting that unfrozen water occurs at night when the atmospheric humidity approaches the saturation vapor pressure. However, the quantitative increase in permittivity is difficult to reconcile with the very small amounts of $\mathrm{H}_{2} \mathrm{O}$ available in the atmosphere for adsorption [Zent et al., 2010]. Also, at the Phoenix frost point $(\sim 195 \mathrm{~K})$ adsorbed $\mathrm{H}_{2} \mathrm{O}$ films are limited to no more than a few nanometers in thickness; any additional $\mathrm{H}_{2} \mathrm{O}$ added to the system finds ice to be the lowerenergy reservoir.

[32] Dielectric measurements made during the day indicate that no unfrozen water occurs during the day. This conclusion holds even though the dielectric and thermal properties measurements exhibit a significant standard deviation likely due to small $(<1 \mathrm{~mm})$ movements of the TECP needles caused by effects of wind on the robotic arm. Thermal and electrical property measurements by TECP are extremely sensitive to details of the grain needle contacts as was found in premission instrument characterization [Zent et al., 2009].

[33] No evidence of electrical conductivity was observed at any time or location by TECP, indicating that unfrozen water was not mobile in the soil. Thus, when absorbed water occurs, it appears to be confined to specific grain boundaries and cannot move among them.

[34] In summary, the TECP results indicate thin films of unfrozen water form in the soil when the atmospheric humidity approaches saturation and that the atmosphere loses water to the soil when high relative humidity conditions pertain. We thus assign $\mathrm{F}_{o b s}$ a value of high but we note that the presence of unfrozen water is probably much more important for habitability during warmer/higher insolation periods, when temperatures and atmospheric humidity are higher, than it is at the present time.

\subsection{Theoretical Case for Liquid Water at the Phoenix Site}

[35] As discussed in section 4.1, liquid water is theoretically possible at the Phoenix landing site only when (1) a source of water is present and (2) environmental conditions allow it to be liquid. Liquid water is unlikely to be stable on Mars, even in a warmer past but it may exist quiescently, so a third factor is included to represent the stability of liquid water. Phoenix findings were used to assign values to these factors as described next.

\subsubsection{Presence of Water Ice in the Subsurface and Surface: Evaluating $\boldsymbol{F}_{\boldsymbol{t h}}$}

[36] A necessary (but not sufficient) condition for liquid water is the presence of $\mathrm{H}_{2} \mathrm{O}$ in any form at the landing site. Therefore, the detection of ice in the subsurface was an important measurement from the habitability standpoint. Several measurements indicated unequivocally that ice was present at the landing site in the subsurface, and was deposited on the surface at night.

[37] The imaging evidence for icy material at the landing site was described previously. TEGA analysis of an icy sample was a planned mission objective but it turned out to be very difficult to achieve. The ISAD was developed to obtain the icy material as drilled cuttings. As discussed above, nearly pure ice was exposed in DG but the local topography sloped by $14^{\circ}$ to the southwest, and thus it was awkward for the RA to deploy the ISAD to obtain icy samples there. Although it was soil-like in appearance, the SW trench contained a hard layer that was interpreted to be ice-cemented soil. Since it offered better access to the ISAD, it was chosen to obtain the icy sample for TEGA analysis. Icy cuttings were expected to sublimate rapidly in the scoop, so the RA team attempted to collect and deliver the sample very quickly; in fact, the entire operation including acquiring the sample and dumping it into the TEGA port took less than $30 \mathrm{~min}$. However, the material stuck in the scoop even after it was turned upside down and nothing entered the instrument. The entire procedure was attempted twice with similar results possibly because the icy sample was adhering to the scoop due to thermal sintering. Finally, a sample was collected by scraping the soil-ice interface to create a pile of material that was allowed to sit on the surface for 1 sol prior to acquisition. $\mathrm{H}_{2} \mathrm{O}$ was detected in the sample [Smith et al., 2009; Boynton et al., 2009], proving that the hard layer contains ice, although its weight fraction in the subsurface is impossible to determine.

[38] An important result of the Phoenix mission is the first detection of water ice in the form of snow on Mars from profile measurements made by the MET lidar [Whiteway et al., 2009]. Seasonal water ice had previously been observed 


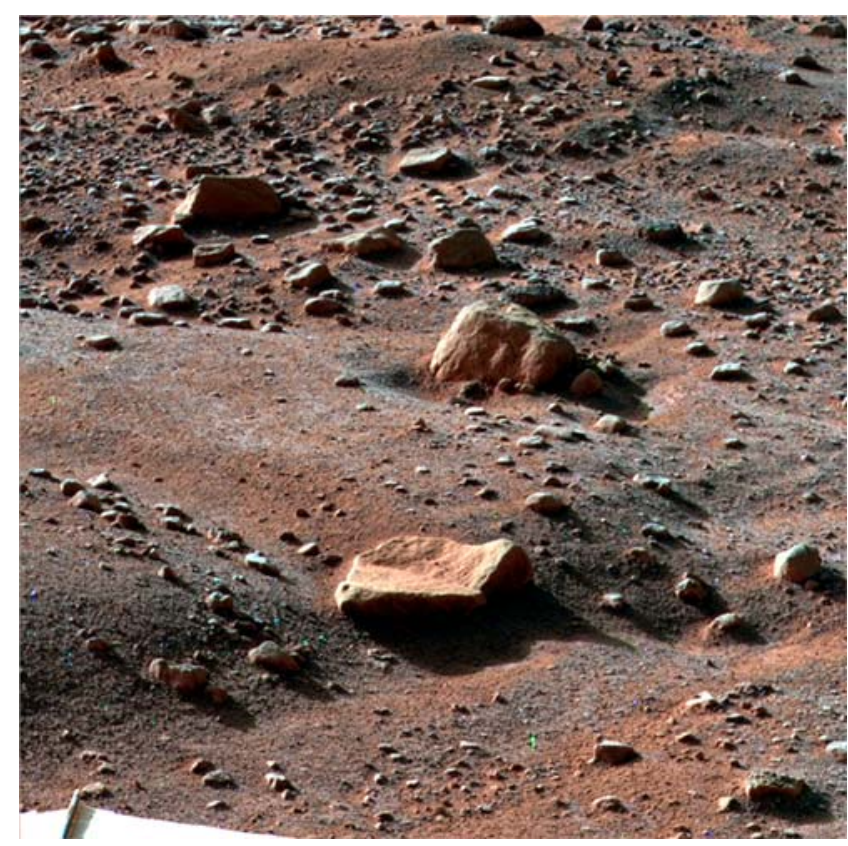

Figure 6. SSI image in false color showing frost on the surface. Image is from $0500 \mathrm{LST}$ sol $79\left(\mathrm{~L}_{\mathrm{s}}=112\right)$.

at the Phoenix landing site latitudes by TES [Tamppari et al., 2007], but this was deposited during winter. The lidar measured vertical profiles of particles in the Martian atmosphere using two channels with wavelengths of $532 \mathrm{~nm}$ and $1064 \mathrm{~nm}$ [Whiteway et al., 2008]. Height resolution could be commanded in three height ranges and was set to between $20 \mathrm{~m}$ and $100 \mathrm{~m}$, with high signal to noise typically achieved in the lowest $10 \mathrm{~km}$.

[39] Strongly scattering layers were observed persistently at night from $\mathrm{L}_{\mathrm{s}} 117^{\circ}$ onward, having shape and evolution consistent with water ice clouds. Supporting the interpretation are "cloud movies" made by the SSI [Moores et al., 2010]. Atmospheric temperatures were too high for carbon dioxide condensation. The clouds formed at the top of the residual daytime boundary layer around $4 \mathrm{~km}$ height with evidence of a descending cloud base through the night [Whiteway et al., 2009].

[40] Evidence of snowfall was first observed on $\mathrm{L}_{\mathrm{s}} 112^{\circ}$ as precipitation fall streaks, typical of cirrus cloud on Earth. In many observed cases the fall streaks did not reach the ground, as ice crystals sublimated during descent. However, some cases were observed [see Whiteway et al., 2009, Figure 2] where fall streaks descended from the cloud base through a ground fog to the bottom of the lidar record at $50 \mathrm{~m}$ and are assumed to reach the ground. Whiteway et al. [2009] estimated the water ice content in the clouds is $\sim 2 \mathrm{pr}$ $\mu \mathrm{m}$ of which a fraction might reach the surface. While visible evidence of frost on the surface is seen in a small number of SSI early morning images (Figure 6), most obviously in images acquired in early morning between $\mathrm{L}_{\mathrm{s}}=112-114^{\circ}$, it is impossible to discriminate whether the source is ground fog or snow.

[41] The precipitation of snow on Mars is significant for habitability as it provides evidence of a source of surface ice that can be out of thermodynamic equilibrium with its environment. In general, surface temperature can be expected to provide a strong control on the state of water, where condensation and sublimation will occur on a diurnal cycle in equilibrium with the environment as temperature passes through the local frost point.

[42] Snow has been postulated for Mars [Kahn, 1990] but not formally included in models of water cycle. The addition of snowfall to a water budget has two potential impacts: heterogeneous accumulation of water ice at the surface and a potential to bring water ice in contact with surfaces at temperatures above the frost point, in regions where pressure is above the triple point, and hence provide a mechanism with the potential to produce transient liquid water.

[43] The microphysics necessary to represent snowfall is not currently included in Mars Global Circulation or Climate Models that do include the water cycle and so the significance of surface accumulation on global and climate scales has still to be assessed. Though clouds appear widespread from orbiter observations, disequilibrium patterns of deposition will depend on transport.

[44] Based on the discussion above, the factor $F_{t h 1}$ for the availability of water ice in an accessible form is assigned high due to the presence of ice in the subsurface and snow on the surface.

\subsubsection{Thermodynamic Conditions Allowing Liquid} Water to Form, Its Stability, and Evaluating $\boldsymbol{F}_{\boldsymbol{t h} \mathbf{2}}$ and $\boldsymbol{F}_{\boldsymbol{t h} \mathbf{3}}$

[45] An important consideration for habitability is whether environmental conditions exceed the triple point of water, defined as the temperature and pressure at which solid, liquid, and vapor phases coexist in equilibrium. When pressure is below the triple point pressure, the liquid phase will not form and upon heating ice will sublimate but not melt. The presence of salts will lower both the freezing point temperature and the triple point pressure. Phoenix discovered perchlorate ions in the soil [Hecht et al., 2009] that are capable of large freezing point depressions [Pestova et al., 2005; Hanley et al., 2009, Rennó et al., 2009]. Ice deposited on the soil as frost or snow, if in direct contact with a magnesium perchlorate salt particle, could plausibly melt at a temperature $\sim 69 \mathrm{~K}$ lower than the freezing temperature of pure water.

[46] TECP measured the temperature in the soil over a diurnal cycle and also measured the thermal conductivity and volumetric heat capacity, which together define the surface thermal inertia as well as the diurnal skin depth. Figure 7 is a solution to a model (described by Zent et al. [2010]) of the subsurface thermal profile for $L_{s}=100^{\circ}$, constrained by the observed depth of ground ice, the thermophysical properties of the dry overburden, and the regolith temperature, integrated over the uppermost $15 \mathrm{~mm}$, as measured by the TECP. The diurnal temperature variation at the ice table is about $20 \mathrm{~K}$ at $\mathrm{L}_{\mathrm{s}}=100^{\circ}$. The daytime peak soil temperature measured is $260 \mathrm{~K}$. The temperature drops rapidly with depth beneath the surface and the temperature at the ice table in equilibrium with the atmosphere is very low $(220-230 \mathrm{~K})$.

[47] Even though at night the surface became coated with frost, there is no evidence from TECP conductivity measurements that liquid occurs in the surface soil during the daytime, as would be the case if some of the surface ice remained in the soil and melted during the high-temperature part of the day. It was not possible to obtain a TECP mea- 


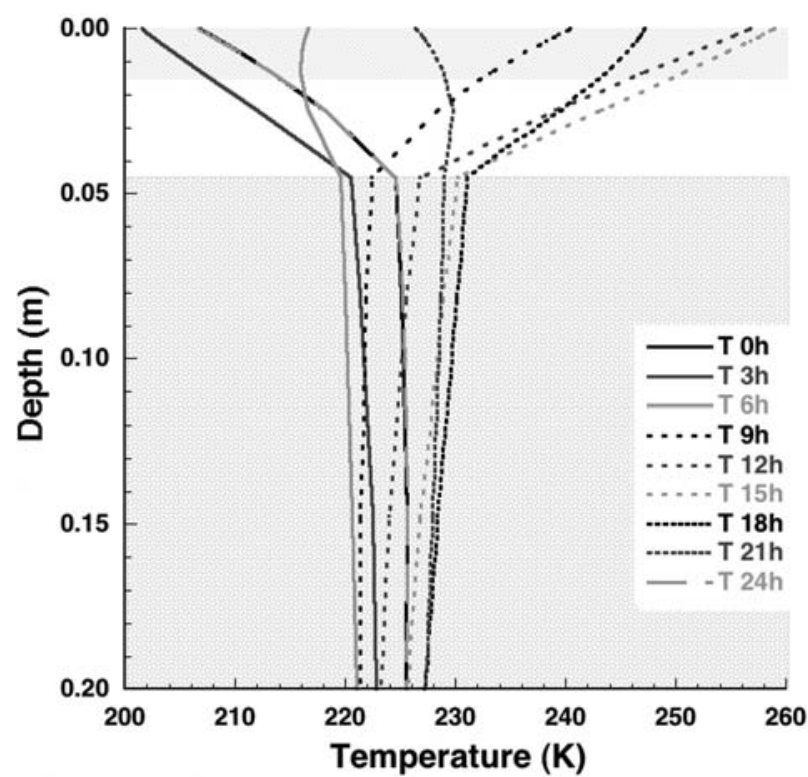

Figure 7. Subsurface temperature profile throughout a sol, at $\mathrm{L}_{\mathrm{s}}=100^{\circ}$, anchored by the measured surface temperature, derived with the method used by Zent et al. [2010]. Ground ice is assumed to saturate soil pores for all $Z>4.5 \mathrm{~cm}$. Surface temperatures vary by $60 \mathrm{~K}$ from midnight to the afternoon high at $1500 \mathrm{LST}$ near $260 \mathrm{~K}$. The ice table temperature variation is $10 \mathrm{~K}$. Temperatures high enough for microbial growth occur at the surface for $\sim 3 \mathrm{~h}$ per day.

surement of the conductivity at the ice table because the instrument needles would not penetrate the hard icy material.

[48] Quasi-periodic cyclical changes in solar insolation occur in the north polar region (NPR) because of orbital forcing [Laskar et al., 2004]. Figure 8 shows the insolation at the Phoenix landing site over the last 5 Myr calculated from the model of Zent [2008]. In the current epoch, northern summer occurs during aphelion, and the obliquity $\left(25.2^{\circ}\right)$ is relatively low. The current peak summer daily averaged solar irradiance is $192.8 \mathrm{~W} \mathrm{~m}^{-2}$, and with this low value the temperature never exceeds the melting point of pure liquid water. However, perihelion longitude precesses with a 51,000 year cycle so, when northern summer corresponds with perihelion, peak summer insolation is $23 \%$ higher which causes summer surface temperatures to exceed $273 \mathrm{~K}$ for several days each year [Haberle et al., 2003; Richardson and Michna, 2005]. In addition, Mars' obliquity oscillates with a $\sim 10^{5}$ yr period and $\sim 1.2$ Myr envelope and the mean obliquity also drifts with time. For the past $5 \mathrm{Myr}$, Mars' obliquity has oscillated about a value of $25^{\circ}$ but from 10 Myr to 5 Myr ago, the mean obliquity was $\sim 35^{\circ}$ and the maximum obliquity was almost $50^{\circ}$. At these high obliquities, the maximum insolation is up to 2.5 times the present value, and surface temperatures exceed $273 \mathrm{~K}$ up to 100 days per year [Richardson and Michna, 2005]. Thus, at high obliquity, pure liquid water will form at the surface at the Phoenix landing site if a water/ice emplacement mechanism exists.

[49] In summary, current thermodynamic conditions allow perchlorate-salt solutions to form at the surface and ice table interface but do not allow pure liquid water to form. How- ever, it can form at the surface during the opposite phase of perihelion for a few days a year and for many days at high obliquity [Richardson and Michna, 2005; Zent, 2008]. We assign high to the factor $F_{t h 2}$, indicating that thermodynamic conditions allow the formation of liquid water at least during high insolation periods.

[50] Finally, the stability of liquid water must be considered. Even at high obliquity, the Martian climate is cold and dry by terrestrial standards. Thus liquid water is, at best, quasi-stable, and while melting is possible during the day, water will refreeze at night. So the factor for the stability of liquid water is evaluated as medium.

[51] To recap, the theoretical probability of liquid water is the product of the three factors described above:

$$
F_{t h}=F_{t h 1} * F_{t h 2} * F_{t h 3}
$$

resulting in a value of medium for the factor $F_{t h}$.

\subsection{Energy Sources for Life}

[52] Next we consider the probability that energy is available to support metabolism. Two factors represent energy sources: $F_{e 1}$ for energy from sunlight to be utilized in photosynthesis and $F_{e 2}$ for chemical energy.

\subsubsection{Solar Energy}

[53] Although sunlight provides an ample energy source, the high flux of ultraviolet (UV) radiation down to $190 \mathrm{~nm}$ renders the exposed Martian surface uninhabitable. A thin soil layer might provide enough UV protection for life to survive, but the available energy would be greatly diminished unless the particles transmit photosynthetically active radiation (PAR, 400-700 $\mathrm{nm}$ ) but block ultraviolet wavelengths [Cockell et al., 2005]. Many rock materials block UV while transmitting PAR [e.g., Cockell, 2001; Hall et al., 2008]. PAR light transmitted through rock supports endolithic communities at depths far greater than $1 \mathrm{~mm}$ below the surface (e.g., Nienow et al. [1988]; for a comprehensive review of environments supporting endoliths see Whitten and Potts [1999]). Schuerger et al. [2003] show that 0.5

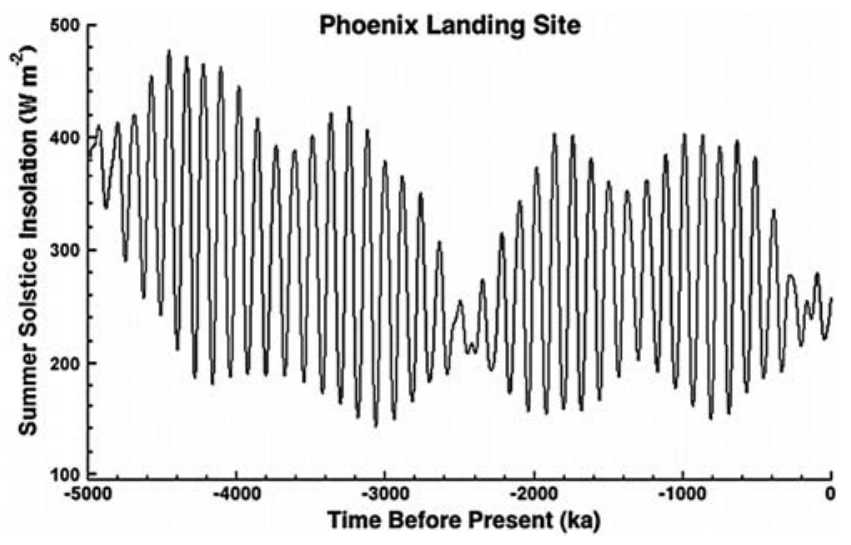

Figure 8. Diurnal average insolation at summer solstice over the last $5 \mathrm{Myr}$ at the Phoenix landing site from the model of Zent [2008]. Five million years before the present time, the average insolation at the Phoenix landing site was significantly higher than it is today. High-frequency insolation changes are due to the phasing of perihelion. 


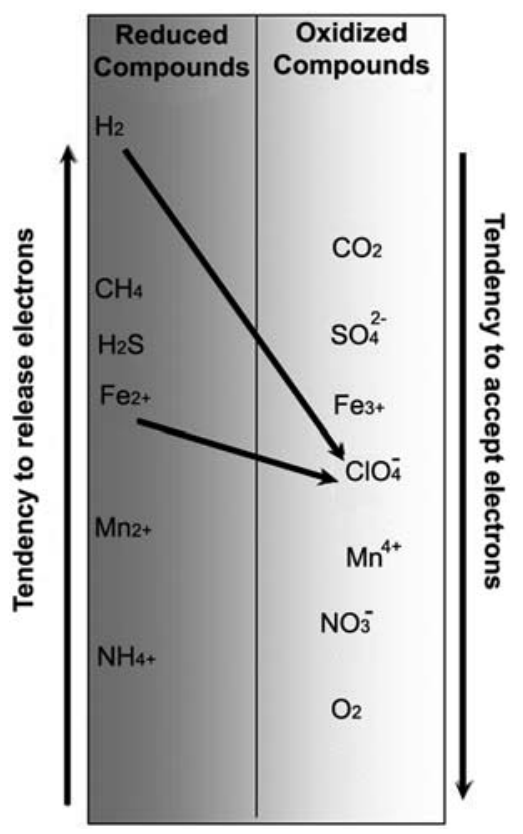

Figure 9. List of reduced and oxidized compounds arranged vertically to show their relative reducing and oxidizing tendencies, respectively. Arrows pointing diagonally downward represent positive energy release and thereby thermodynamically favorable reactions. On Mars, $\mathrm{Fe}^{2+}$ in basaltic rocks and $\mathrm{H}_{2}$ released from the serpentinization of these rocks can form an energy-yielding redox couple with the perchlorate discovered at the Phoenix landing site.

to $1 \mathrm{~mm}$ of soil is required to prevent sterilization by ultraviolet radiation. Translucent particles up to 150 microns in diameter are seen in OM images of Phoenix soils but the OM sample handling system did not admit particles larger than 200 microns. A layer of the smaller particles might provide adequate UV shielding, provided they have wavelength-dependent light transmission properties that admit PAR and exclude UV. Other options for obtaining shielding from UV radiation include living under the semitransparent surface of a porous rock. This is the habitat of cryptoendolithic lichen that live under the surface of sandstones in Antarctica obtaining radiation shielding, dehydration resistance, and water from melting snow that seeps into the rock [Friedmann, 1982]. Voids in impact breccia have also been shown to host microbial habitats similar to Antarctic sandstones [Parnell et al., 2004]. As the Phoenix landing site is located on impact ejecta, brecciated rocks are probably common at the landing site.

[54] Based on the above arguments, we assign the probability for available energy from sunlight (in a UV shielded environment) at the Phoenix landing site as high.

\subsubsection{Chemical Energy for Subsurface Life}

[55] In deeper subsurface environments, chemical energy is needed to support metabolism. Martian soil contains suitable redox couples to allow the sorts of reactions catalyzed by biological systems on Earth [see, e.g., Stumm and Morgan, 1995].

[56] Figure 9 shows possible redox couples that could provide energy for chemosynthetic life on Mars. Potential high yield energy couples involve perchlorate as an electron acceptor and reduced inorganic substances such as $\mathrm{H}_{2}, \mathrm{CH}_{4}$, $\mathrm{H}_{2} \mathrm{~S}$, or $\mathrm{Fe}^{2+}$ as electron donors. Other possible couples might include $\mathrm{H}_{2}$ (electron donor) with $\mathrm{SO}_{4}^{2-}$ or $\mathrm{Fe}^{3+}$ (electron acceptor). However, the lack of evidence for organic carbon on Mars makes the use of $\mathrm{SO}_{4}^{2-}$ as an electron acceptor unlikely. Even though there are $\mathrm{CO}_{2}$ utilizing sulfate-reducing bacteria on Earth, these are mixotrophic (requiring at least trace amounts of organic carbon) rather than truly autotrophic [Coates and Achenback, 2004]. In addition, although hydrated sulfate minerals (gypsum, epsomite) are used directly as a sulfate source by bacteria on Earth [Douglas and Yang, 2002; Douglas et al., 2008], anhydrous sulfate minerals such as anhydrite have not been shown to provide a sulfate source although anhydrite only exists in environments with extremely low water activity, insufficient to support metabolic functions or to harbor the anoxic microenvironment required by sulfate reducing bacteria. Also, the robust crystalline structure of anhydrite may make use of its constituent sulfate thermodynamically unfavorable for living organisms.

[57] The $\mathrm{H}_{2}$ on Mars may be derived (as on Earth) from abiotic reactions such as serpentinization where alkaline groundwater reacting with $\mathrm{Fe}^{2+}$-rich rock leads to hydrogen production [Fisk and Giovannoni, 1999; Schulte et al., 2006]. This reaction is sufficient to support a deep biosphere on Earth [Stevens and McKinley, 1995; Chapelle et al., 2002]. In spite of the red color (due to oxidized iron), most of the iron on the Martian surface is in the reduced form $\left(\mathrm{Fe}^{2+}\right)$. The presence of black and some greenish rounded glassy particles seen in the OM images suggests that $\mathrm{Fe}^{2+}$ may be plentiful at the landing site, as part of olivine and pyroxene-rich minerals. Both of these mineral types can serve as sources of $\mathrm{Fe}^{2+}$ for autotrophic $\mathrm{Fe}$-oxidizing bacteria on Earth and $\mathrm{Fe}$-oxidizing/perchlorate reducing bacteria may be ideal model organisms for a Martian biota.

[58] Phoenix discovered substantial levels ( 0.4 to $0.6 \%$ ) of perchlorate (presumably sodium, magnesium, or calcium forms) in the Martian soil [Hecht et al., 2009]. The large positive reduction potential of perchlorates $(1.287 \mathrm{~V})$ makes them ideal electron acceptors for microbial metabolism [Coates et al., 2000] and these compounds can be utilized as an energy source by numerous species of microbes [Coates and Achenback, 2004], that have been isolated from a variety of environments [Wallace et al., 1996; Coates et al., 1999; Bruce et al., 1999; Michaelidou et al., 2000; Romanenko et al., 1976; Stepanyuk et al., 1992; Malmqvist et al., 1994, Rikken et al., 1996] including Antarctic soils [Bender et al., 2004]. Perchlorate reducing bacteria grow by oxidation of organic carbon or inorganic electron donors $\left(\mathrm{H}_{2}, \mathrm{H}_{2} \mathrm{~S}\right.$, or $\left.\mathrm{Fe}_{2}+\right)$ coupled to the reduction of perchlorate [Coates and Achenback, 2004]. They grow under widely varying environmental conditions, and have a broad range of metabolic capabilities including (of relevance to Mars) the oxidation of soluble and insoluble ferrous iron [Coates et al., 1999, Bruce et al., 1999; Michaelidou et al., 2000; Chaudhuri et al., 2001, Lack et al., 2002]. Many of these organisms are able to use $\mathrm{CO}_{2}$ gas as a carbon source [Miller and Logan, 2000] and so can grow and metabolize under completely inorganic conditions. Some Atacama (Chile) soils contain perchlorate concentrations as high as the Phoenix soils $(\sim 1 \%)$ and there is no toxicity to microbes even at much higher concentrations. Growth cultures at $2 \%$ 
perchlorate level showed no detrimental effects [Gal et al., 2008]. In addition, although many perchlorate-reducing bacteria are inhibited by the presence of nitrate, which is preferentially used when both ions are present, there are some bacteria that use perchlorate exclusively and are unaffected by nitrate in the environment. On Earth, nitrate and perchlorate occur together but whether or not this is true for Mars is uncertain.

[59] In summary, based on the measured presence of perchlorate, the likely presence of reduced (but insoluble) iron as a redox couple, and the known capability of perchlorate reducing organisms on Earth to utilize insoluble reduced iron minerals as electron donors, the probability of available chemical energy to support life at the Phoenix site is designated high.

\subsection{Nutrients for Life}

[60] In addition to water and energy, life requires the elements involved in building biomass, most importantly $\mathrm{C}$, $\mathrm{H}, \mathrm{N}, \mathrm{O}, \mathrm{P}$, and $\mathrm{S}$. In the habitability calculation, each of these elements is treated as a factor and the combined probability is the weighted sum of all the factors.

\subsubsection{Carbon}

[61] The presence of carbonate(s) [Boynton et al., 2009] and the alkaline $\mathrm{pH}$ [Kounaves et al., 2009] at the Phoenix site means that, in addition to the atmospheric reservoirs of $\mathrm{C}$ (as $\mathrm{CO}_{2}$ and $\mathrm{CO}$ ), there is an abundant source of readily available inorganic $\mathrm{C}$ in the soil. This factor is assigned high.

\subsubsection{Hydrogen}

[62] $\mathrm{H}$ is potentially available from $\mathrm{H}_{2} \mathrm{O}$ adsorbed to surface minerals and vapor in the atmosphere, but accessing it would require breaking the $\mathrm{H}_{2} \mathrm{O}$ molecule, which is done on Earth via oxygenic photosynthesis. Microorganisms can also use $\mathrm{H}_{2}$ derived from the abiotic reaction between groundwater and rock (e.g., serpentinization) [Stevens and McKinley, 1995]. This factor is assigned high.

\subsubsection{Nitrogen}

[63] There is no evidence for fixed nitrogen (e.g., nitrates) on Mars and this remains an uncertain resource. On Earth, some microbes "fix," i.e., convert atmospheric $\mathrm{N}_{2}$ into soluble soil nitrogen compounds, but it requires considerable metabolic energy and it is unknown whether microbial nitrogen fixation can be performed at the low $\mathrm{N}_{2}$ partial and total pressure on Mars. Phoenix was unable to provide new information about nitrogen compounds in soil because the ISE designated for nitrate was sensitive to perchlorate, nitrate, chloride, and phosphate (in decreasing order of sensitivity) [Hecht et al., 2009] so the high percentage of perchlorate prevented the detection of either nitrate or phosphate. However, an upper limit of soluble nitrate in the soil can be obtained by comparing WCL measured soil solution conductivity with anion and cation concentrations and ion charge balance. While determining a precise limit requires further work, if present at all, nitrate concentration is low as almost all the anionic part of the charge balance could be accounted for by measured perchlorate and sulfate levels. In Atacama, Chile, where perchlorate forms in the driest terrestrial deserts, nitrate occurs in uncommonly high abundances [Ericksen, 1981]. On the basis of isotopic systematics, both perchlorate and nitrate in the Atacama derive from photochemical process [Michalski et al., 2004; Bao and
$G u, 2004$; Dasgupta et al., 2005], so it is plausible that fixed nitrogen occurs as a photochemical product in Mars soils. Manning et al. [2008] show that impacts may cycle $\mathrm{N}_{2}$ between the atmosphere and fixed nitrogen in soils. We assign the factor for nitrogen availability in a biologically accessible form as medium since it is plausibly present in Mars soils but this is not demonstrated by data.

\subsubsection{Oxygen}

[64] In addition to limited sources in the atmosphere $\left(\mathrm{O}_{2}, \mathrm{O}_{3}\right.$, $\mathrm{H}_{2} \mathrm{O}_{2}$ ) and various photochemically derived oxidizing nonmolecular forms ( $\mathrm{OH}$ radical, $\mathrm{O}^{*}, \mathrm{O}-$, etc.), the perchlorate salts provide a storehouse of readily available oxidizing power at the Phoenix site. For Photosynthetic organisms, $\mathrm{H}_{2} \mathrm{O}$ and $\mathrm{CO}_{2}$ can provide sources of oxygen. This factor is assigned high.

\subsubsection{Phosphorus}

[65] The WCL was not equipped with a sensor that could adequately measure phosphate or $\mathrm{P}$ compounds but $\mathrm{P}$ is unlikely to be a limiting nutrient. Phosphorus-containing minerals are abundant in all MER samples, including strong enrichments in Ca-phosphates in some suites of materials in the Columbia Hills. Martian meteorites contain water extractable phosphates [Mautner and Sinaj, 2002]. Most plausible $\mathrm{P}$ minerals are not soluble at $\mathrm{pH} 7.8$ measured by Phoenix, but many terrestrial microbes dissolve $\mathrm{P}$ by excreting organic acids [Alexander, 1991]. It is likely that $\mathrm{P}$ will be present at trace levels but in sufficient quantities for metabolism so this factor is assigned high.

\subsubsection{Sulfur}

[66] There is strong circumstantial evidence of sulfates at the Viking and Pathfinder sites [Clark and van Hart, 1981; McSween et al., 1999] and they are thought to be a component of Martian dust. Ferric sulfate has been identified in Martian sedimentary deposits at both Meridiani Planum and Gusev Crater [Klingelhofer et al., 2004; Morris et al., 2004]. Other sulfates including kieserite, gypsum, and polyhydrated sulfates are seen in some massive layered sedimentary deposits on Mars [Gendrin et al., 2005] as well as ferric sulfates [Bibring et al., 2007], and gypsum is associated with dune-forming deposits in the Olympia Planitia region near the north pole of Mars [Langevin et al., 2005]. Sulfides and sulfate are present in Martian meteorites, with sulfates in some [Bridges et al., 2001]. TEGA could detect specific sulfates but, since none were detected, Golden et al. [2009] infer that anhydrite, an undetectable species, is the dominant sulfate in Martian dust. The WCL analysis indicates sulfate to be present at $5-6 \mathrm{mM}$ in solution [Kounaves et al., 2010b].

[67] Based on the above discussion, the probability of all the biogenic elements being present at the Phoenix landing site is assigned a high value for all the elements. In addition to these macronutrients, a wide range of micronutrients are also required for growth and replication of life on Earth. Based on available literature, and recovered SNC meteorites, these are also probably present on Mars.

\subsection{Other Environmental Factors}

[68] The final term in equation (2) concerns whether conditions in the environment are too toxic or extreme to support growth, and whether a signature of life can be preserved. Four factors may limit growth: temperature, 
water activity, $\mathrm{pH}$, and preservation of organic compounds, so each of these factors is assigned a value from null to high.

[69] Beaty et al. [2006] review the literature on the temperature limits to growth of terrestrial microbes. Growth occurs at temperatures as low as $253 \mathrm{~K}$ [Finegold, 1996; Rivkina et al., 2000; Junge et al., 2004] and maintenance metabolism may occur as low at $233 \mathrm{~K}$ [Price and Sowers, 2004]. The peak daytime soil surface temperature recorded by the TECP in the soil (integrated over $15 \mathrm{~mm}$ depth) is $260 \mathrm{~K}$ (Figure 7) but it drops to almost $200 \mathrm{~K}$ at $0300 \mathrm{LST}$. The temperature decreases rapidly with depth and the current ice table temperature (220-230 K, Figure 7) is too low for metabolism and exceeds that needed for growth only at high obliquity [Zent, 2008]. Since current surface temperatures allow growth and ice temperatures at high obliquity allow it, this factor is assigned high.

[70] In the presence of salts, microbial growth is limited by water activity, defined as

$$
a_{\mathrm{w}}=\mathrm{P} / \mathrm{P}_{\mathrm{o}}=n_{1} / n_{1}+n_{2}
$$

where $\mathrm{P}$ is the vapor pressure of solute and Po is the vapor pressure of pure liquid water at the same temperature, $n_{1}$ is the moles of solvent (water), and $n_{2}$ is the moles of solute. The lowest recorded water activity for growth is 0.61 for fungi and yeast in sugar processed food [Grant, 2004]. However, as with many geochemical measurements, only the solution chemistry is assessed. Conditions in the microenvironments experienced by microorganisms are often quite different than on average [Schultze-Lam and Beveridge, 1994; Flemming et al., 1990; Potts, 1994]. Only prokaryotes are known to grow in very high salt concentrations and some are capable of growing in saturated $\mathrm{NaCl}$ solution at $a_{\mathrm{w}}=0.75$ [Grant, 2004]. WCL found more than $1 \%$ by mass of perchlorate, magnesium, and sodium ions in the soil of the landing site: probably from calcium, magnesium, and sodium perchlorate hydrates [Hecht et al., 2009]. However, many other salts are also probably present in the soil as suggested by WCL results for total conductivity and data from previous Mars missions and SNC meteorites [e.g., Rao et al., 2005; Wentworth et al., 2005]. Calcium and magnesium perchlorate hydrates have freezing temperatures around $200 \mathrm{~K}$, are extremely deliquescent [Besley and Bottomley, 1969; Pestova et al., 2005], and mixtures of various salts have eutectic temperatures below that of the individual salts [Seinfeld and Pandis, 2006]. As an example, a eutectic $\mathrm{Mg}\left(\mathrm{ClO}_{4}\right)_{2}$ solution is $50 \%$ by mass of solute, has a freezing point depression of $-68.6 \mathrm{~K}$, and a water activity of 0.5 [Pestova et al., 2005]. Frost or snow falling on salts in the soil may form tiny patches of brines even at low temperatures. There is no data on the water activity limits to growth of perchlorate metabolizing organisms. Assuming that growth can occur up to water activity of 0.75 , similar to terrestrial halophilic organisms, this equates to a perchlorate concentration of $25 \%$ and freezing point depression of $-51 \mathrm{~K}$ (freezing at $222 \mathrm{~K}$ ).

[71] At high concentrations of certain salts, relative to the amount of $\mathrm{H}_{2} \mathrm{O}$, the soluble electrolytes can reduce the water activity below the empirically observed limits of terrestrial organism metabolism [Tosca et al., 2008]. Perchlorates are among the most soluble of candidate compounds but, as the WCL experiment has shown, the average soil level will not cause low water activity when water is abundant. The Phoenix site is clearly $\mathrm{H}_{2} \mathrm{O}$-rich, and GRS observations from orbit indicate an $\mathrm{H}_{2} \mathrm{O}$ ice abundance greater than is required to fill soil pore space [Boynton et al., 2002]. From the standpoint of salt concentration, a biologically favorable environment could occur with even millimeter-scale heterogeneities in $\mathrm{H}_{2} \mathrm{O}$ :salt ratio. Based on these arguments, we assign the factor representing water activity in a range allowing growth to high.

[72] The $\mathrm{pH}$ of a soil/solution mixture is important because specific $\mathrm{pH}$ conditions affect the speciation of many elements. For the soil sample analyzed on Mars, WCL measurements show there is a well-buffered system with slightly alkaline $\mathrm{pH}$ (7.7 to 7.9) [Hecht et al., 2009]. The $\mathrm{pH}$ is slightly lower than seawater on Earth, an environment where microbial life flourishes buffered by the carbonate system. The $\mathrm{pH}$ of $\mathrm{Mg} / \mathrm{CaCO}_{3}$ buffered system will not change until all carbonates are dissolved. The $\mathrm{pH}$ of the Martian soil at this location is benign and the carbonate buffering provides a stable environment, so this factor is evaluated as high.

[73] Finally, we consider the possible presence of organic compounds. While it is not, strictly speaking, a signature of a habitable environment, the tendency of an environment to preserve or destroy an organic record is clearly important for selecting environments to search for life. TEGA did not detect organic compounds, but a low temperature release of $\mathrm{CO}_{2}$ between $200^{\circ} \mathrm{C}$ and $600^{\circ} \mathrm{C}$ was observed for several of the Phoenix soils. This could be attributed to three different processes: (1) desorption of adsorbed $\mathrm{CO}_{2}$, , (2) thermal decomposition of $\mathrm{Fe}$ - and $\mathrm{Mg}$-carbonates, and (3) combustion of organic molecules [Ming et al., 2009]. Laboratory work is currently ongoing to attempt to distinguish between these three scenarios, primarily trying to distinguish among the three by reproducing the temperature at which $\mathrm{CO}_{2}$ evolution occurs.

[74] The discovery of perchlorate in the Martian soils [Hecht et al., 2009] complicates the search for organics because pyrolysis of perchlorate salts causes a substantial release of oxygen, detected between $360^{\circ} \mathrm{C}$ and $575^{\circ} \mathrm{C}$ by TEGA. The combustion of organic material to $\mathrm{CO}_{2}$ might also explain the lack of organics observed by the Viking GC/MS. Both Viking Landers detected a large amount of $\mathrm{CO}_{2}$ released as soils were heated but no reduced carbon was detected at the ppb level [Biemann et al., 1977]. Organic oxidation in the pyrolitic stage of the GCMS has been suggested [Navarro-Gonzalez et al., 2006] to explain the lack or organics detected by Viking GCMS, but Biemann [2007] refute this since organic contamination was detected in the GC/MS ovens. Still, the presence of perchlorate provides an oxygen source that may facilitate the combustion of organics into $\mathrm{CO}_{2}$ during pyrolysis experiments complicating organic detection.

[75] Many important organic compounds also contain nitrogen, but N-bearing organic fragments are difficult to distinguish with TEGA because combustion of organics in the presence of oxygen would yield $\mathrm{NO}$ with mass $30 \mathrm{AMU}$, which is identical to $\mathrm{CO}$ with ${ }^{18} \mathrm{O}$. There is so much $\mathrm{CO}$, both in the background and as a fragment from $\mathrm{CO}_{2}$, that it would mask NO unless the abundance were a few percent. Similarly, there are problems distinguishing $\mathrm{CN}$ compounds because the $\mathrm{CN}$ radical weighs $26 \mathrm{AMU}$, and cannot be 
Table 3. Factors Used in Computation of Probabilities for Liquid Water, Energy, Chemistry, and Benign Environment

\begin{tabular}{|c|c|c|c|}
\hline & Site & Value & Rationale \\
\hline \multicolumn{4}{|c|}{ Observational Factors for $P_{l w}$, Probability of Liquid Water } \\
\hline \multirow[t]{6}{*}{$F_{o b s 1}$, Morphological evidence of liquid water } & Phoenix & Medium & $\begin{array}{l}\text { Pure ice at DG. Medium score reflects possible alternative } \\
\text { explanations for pure ice. }\end{array}$ \\
\hline & Meridiani & High & $\begin{array}{l}\text { Several lines of evidence for liquid water including vugs and } \\
\text { voids and festoon features. }\end{array}$ \\
\hline & Gusev & High & Lake bed, outflow channel, and deltaic deposits. \\
\hline & Pathfinder & Low & $\begin{array}{l}\text { Morpological evidence of catastrophic flood, but the duration } \\
\text { of liquid water is short, so assigned low. }\end{array}$ \\
\hline & Viking 1 & Null & No macrsocopic observational evidence reported \\
\hline & Viking 2 & Null & No macrsocopic observational evidence reported \\
\hline \multirow[t]{6}{*}{$F_{o b s 2}$, Microscopic evidence of liquid water } & Phoenix & Medium & Evidence of chemically etched grains \\
\hline & Meridiani & High & Vugs, voids, and hematite concretions \\
\hline & Gusev & Null & No microscopic evidence of aqueous processes \\
\hline & Pathfinder & NA & No relevant observations acquired \\
\hline & Viking 1 & NA & No relevant observations acquired \\
\hline & Viking 2 & NA & No relevant observations acquired \\
\hline \multirow[t]{6}{*}{$F_{o b s 3}$, Evidence for aqueous mineralogy } & Phoenix & Medium & Strong evidence of carbonates but global dust is plausible source. \\
\hline & Meridiani & High & Sulfate minerals formed in low $\mathrm{pH}$ water identified \\
\hline & Gusev & High & Minerals formed in aqueous environments identified \\
\hline & Pathfinder & NA & No relevant observations acquired \\
\hline & Viking 1 & NA & No relevant observations acquired \\
\hline & Viking 2 & NA & No relevant observations acquired \\
\hline \multirow[t]{6}{*}{$F_{o b s 4}$, Evidence for thin films of water } & Phoenix & High & Unfrozen water occurs periodically \\
\hline & Meridiani & NA & No relevant observations acquired \\
\hline & Gusev & NA & No relevant observations acquired \\
\hline & Pathfinder & NA & No relevant observations acquired \\
\hline & Viking 1 & NA & No relevant observations acquired \\
\hline & Viking 2 & NA & No relevant observations acquired \\
\hline \multirow{7}{*}{$\begin{array}{l}F_{t h 1} \text {, Presence of water or emplacement } \\
\text { mechanism for water }\end{array}$} & Theoretical & Factors fo & v, Probability of Liquid Water \\
\hline & Phoenix & High & Subsurface and surface ice \\
\hline & Meridiani & High & Groundwater or shallow tidal flat on ancient Mars \\
\hline & Gusev & High & Groundwater or precipitation on ancient Mars \\
\hline & Pathfinder & High & Outflow flood \\
\hline & Viking 1 & High & Outflow flood \\
\hline & Viking 2 & High & Surface and probable subsurface ice \\
\hline \multirow[t]{6}{*}{$\begin{array}{l}F_{t h 2} \text {, Conditions of T,P above tripple point } \\
\text { occur when liquid water occurred }\end{array}$} & Phoenix & High & $\begin{array}{l}\text { Periodic occurrence of conditions allowing liquid water at some } \\
\text { orbital phases }\end{array}$ \\
\hline & Meridiani & High & Features formed in warm wet early Mars \\
\hline & Gusev & High & Features formed in warm wet early Mars \\
\hline & Pathfinder & Low & $\begin{array}{l}\text { Flood occurred under modern climate conditions. Thermodynamic } \\
\text { conditions allowing liquid water occur seasonally }\end{array}$ \\
\hline & Viking 1 & Low & $\begin{array}{l}\text { Flood occurred under modern climate conditions. Thermodynamic } \\
\text { conditions allowing liquid water occur seasonally }\end{array}$ \\
\hline & Viking 2 & High & VL2 site thermodynamically comparable to Phoenix \\
\hline \multirow[t]{6}{*}{$F_{t h 3}$, Stability or duration of liquid water } & Phoenix & Medium & $\begin{array}{l}\text { Water rapidly evaporates due to low atmospheric pressure and } \\
\text { low relative humidity }\end{array}$ \\
\hline & Meridiani & High & Higher atmospheric pressure on early Mars \\
\hline & Gusev & High & Higher atmospheric pressure on early Mars \\
\hline & Pathfinder & Medium & $\begin{array}{l}\text { Water rapidly evaporates due to low atmospheric pressure and } \\
\text { low relative humidity }\end{array}$ \\
\hline & Viking 1 & Medium & $\begin{array}{l}\text { Water rapidly evaporates due to low atmospheric pressure and } \\
\text { low relative humidity }\end{array}$ \\
\hline & Viking 2 & Medium & $\begin{array}{l}\text { Water rapidly evaporates due to low atmospheric pressure and } \\
\text { low relative humidity }\end{array}$ \\
\hline \multirow{7}{*}{$\begin{array}{l}F_{e 1}, \mathrm{UV} \text { shielded photosynthetically active } \\
\text { radiation available. }\end{array}$} & \multicolumn{3}{|c|}{ Factors for $P_{e}$, Probable Availability of Energy } \\
\hline & Phoenix & High & $\begin{array}{l}\text { Microscopic evidence of translucent particles that may provide } \\
\text { shielding }\end{array}$ \\
\hline & Meridiani & Medium & $\begin{array}{l}\text { No data but plausible that all sites contain niches where PAR } \\
\text { can penetrate but there is sufficient UV shielding }\end{array}$ \\
\hline & Gusev & Medium & Same as above \\
\hline & Pathfinder & Medium & Same as above \\
\hline & Viking 1 & Medium & Same as above \\
\hline & Viking 2 & Medium & Same as above \\
\hline
\end{tabular}


Table 3. (continued)

\begin{tabular}{|c|c|c|c|}
\hline & Site & Value & Rationale \\
\hline \multirow[t]{6}{*}{$F_{e 2}$, Presence of chemical energy source } & Phoenix & High & Redox couple consists of perchlorate and reduced iron. \\
\hline & Meridiani & Medium & $\begin{array}{l}\text { No data that perchlorate is present, but as it is a photochemical } \\
\text { product, it may be present globally }\end{array}$ \\
\hline & Gusev & Medium & $\begin{array}{l}\text { No data that perchlorate is present, but as it is a photochemical } \\
\text { product, it may be present globally }\end{array}$ \\
\hline & Pathfinder & Medium & $\begin{array}{l}\text { No data that perchlorate is present, but as it is a photochemical } \\
\text { product, it may be present globally }\end{array}$ \\
\hline & Viking 1 & Medium & $\begin{array}{l}\text { No data that perchlorate is present, but as it is a photochemical } \\
\text { product, it may be present globally }\end{array}$ \\
\hline & Viking 2 & High & $\begin{array}{l}\text { Environment similar to Phoenix so perchlorate abundance likely } \\
\text { to be similar }\end{array}$ \\
\hline \multicolumn{4}{|c|}{ Factors for $P_{c h}$, Probable Presence of the Chemical Building Blocks of Life } \\
\hline \multirow[t]{6}{*}{$F_{\text {Carbon }}$} & Phoenix & High & Atmospheric carbon dioxide, carbonate in the soil \\
\hline & Meridiani & High & Same as above \\
\hline & Gusev & High & Same as above \\
\hline & Pathfinder & High & Same as above \\
\hline & Viking 1 & High & Same as above \\
\hline & Viking 2 & High & Same as above \\
\hline \multirow[t]{6}{*}{$F_{\text {Hydrogen }}$} & Phoenix & High & Adsorbed water, atmospheric water vapor, and ice \\
\hline & Meridiani & High & Liquid water, hydrated phases of minerals \\
\hline & Gusev & High & Liquid water, hydrated phases of minerals \\
\hline & Pathfinder & High & No data but presume same behavior as Viking soils \\
\hline & Viking 1 & High & Soil gave off water on heating, adsorbed water or hydrated phases \\
\hline & Viking 2 & High & Soil gave off water on heating, adsorbed water or hydrated phases \\
\hline \multirow[t]{6}{*}{$F_{\text {Nitrogen }}$} & Phoenix & Medium & No relevant observations, Nitrate masked by perchlorate \\
\hline & Meridiani & Medium & Same value for all landing sites assumed \\
\hline & Gusev & Medium & Same value for all landing sites assumed \\
\hline & Pathfinder & Medium & Same value for all landing sites assumed \\
\hline & Viking 1 & Medium & Same value for all landing sites assumed \\
\hline & Viking 2 & Medium & Same value for all landing sites assumed \\
\hline \multirow[t]{6}{*}{$F_{\text {Oxygen }}$} & Phoenix & High & Available from atmospheric $\mathrm{CO}_{2}$ \\
\hline & Meridiani & High & Available from atmospheric $\mathrm{CO}_{2}$ \\
\hline & Gusev & High & Available from atmospheric $\mathrm{CO}_{2}$ \\
\hline & Pathfinder & High & Available from atmospheric $\mathrm{CO}_{2}$ \\
\hline & Viking 1 & High & Available from atmospheric $\mathrm{CO}_{2}$ \\
\hline & Viking 2 & High & Available from atmospheric $\mathrm{CO}_{2}$ \\
\hline \multirow[t]{6}{*}{$F_{\text {Phosphorus }}$} & Phoenix & High & Inferred component of Mars soils \\
\hline & Meridiani & High & Abundant Phosphate minerals measured in all samples \\
\hline & Gusev & High & Abundant Phosphate minerals measured in all samples \\
\hline & Pathfinder & High & Inferred component of Mars soils \\
\hline & Viking 1 & High & Inferred component of Mars soils \\
\hline & Viking 2 & High & Inferred component of Mars soils \\
\hline \multirow[t]{6}{*}{$F_{\text {Sulfur }}$} & Phoenix & High & Present in global dust \\
\hline & Meridiani & High & Present in global dust \\
\hline & Gusev & High & Present in global dust \\
\hline & Pathfinder & High & Present in global dust \\
\hline & Viking 1 & High & Present in global dust \\
\hline & Viking 2 & High & Present in global dust \\
\hline & Factors & for $P_{b}$, Probabi & ity of Benign Environment \\
\hline \multirow[t]{6}{*}{$F_{T}$, temperature in biology growth range } & Phoenix & High & At high insolation temperature should be high enough even in the ice table. \\
\hline & Meridiani & High & $\begin{array}{l}\text { Evidence of liquid water suggests that temperature was well with } \\
\text { in growth range }\end{array}$ \\
\hline & Gusev & Medium high & $\begin{array}{l}\text { Evidence of liquid water not as strong as Meridiani, so lower score reflects } \\
\text { more uncertainty about the temperature and climate history }\end{array}$ \\
\hline & Pathfinder & Medium & $\begin{array}{l}\text { Growth requires that liquid water was present during a warm period } \\
\text { of the year. Temperatures get high enough during summer, } \\
\text { but flood could have occurred during any season }\end{array}$ \\
\hline & Viking 1 & Medium & Same logic as Pathfinder \\
\hline & Viking 2 & High & Climatologically, Viking 2 is the same as Phoenix site \\
\hline
\end{tabular}


Table 3. (continued)

\begin{tabular}{|c|c|c|c|}
\hline & Site & Value & Rationale \\
\hline \multirow{6}{*}{$\begin{array}{l}F_{a w} \text {, water activity is in range high enough } \\
\text { for growth }\end{array}$} & Phoenix & High & See text \\
\hline & Meridiani & Low & $\begin{array}{l}\text { Water activity is low due to the low } \mathrm{pH} \text { and high salt content } \\
\text { observed [Tosca et al., 2008] }\end{array}$ \\
\hline & Gusev & Medium & $\begin{array}{l}\text { There is no evidence for high salt content. The uncertainty on } \\
\text { the value is reflected in the score. }\end{array}$ \\
\hline & Pathfinder & Medium & $\begin{array}{l}\text { There is no evidence for high salt content. The uncertainty on } \\
\text { the value is reflected in the score. }\end{array}$ \\
\hline & Viking 1 & Medium & $\begin{array}{l}\text { There is no evidence for high salt content. The uncertainty on } \\
\text { the value is reflected in the score. }\end{array}$ \\
\hline & Viking 2 & High & $\begin{array}{l}\text { Factors controlling water activity are same as for Phoenix site so } \\
\text { gets same score }\end{array}$ \\
\hline \multirow[t]{6}{*}{$F_{\mathrm{pH},}$ moderate $\mathrm{pH}$ conditions } & Phoenix & High & Measurement by WCL \\
\hline & Meridiani & Low & $\begin{array}{l}\text { Acid } \mathrm{pH} \text { implied by Jarosite, causes osmotic stress and limits } \\
\text { microbial diversity }\end{array}$ \\
\hline & Gusev & NA & No basis for estimate \\
\hline & Pathfinder & NA & No basis for estimate \\
\hline & Viking 1 & Medium high & $\begin{array}{l}\text { Inferred to be slightly alkaline. Lower score than Phoenix } \\
\text { because it was not directly measured }\end{array}$ \\
\hline & Viking 2 & Medium high & $\begin{array}{l}\text { Inferred to be slightly alkaline. Lower score than Phoenix } \\
\text { because it was not directly measured }\end{array}$ \\
\hline \multirow[t]{6}{*}{$F_{\text {org, }}$ organics preserved in environment } & Phoenix & Low & Organic question is still under investigtaion \\
\hline & Meridiani & NA & Not measured \\
\hline & Gusev & NA & Not measured \\
\hline & Pathfinder & NA & Not measured \\
\hline & Viking 1 & 0 & Observed to be absent \\
\hline & Viking 2 & 0 & Observed to be absent \\
\hline
\end{tabular}

distinguished from $\mathrm{C}_{2} \mathrm{H}_{2}$ while $\mathrm{HCN}$ cannot be distinguished from $\mathrm{C}_{2} \mathrm{H}_{3}$. Signatures for both of these hydrocarbon gases are observed by TEGA as a background that must be subtracted from signals resulting from heating a sample. Signatures significantly different from the background were not seen during any of the runs. Since TEGA provided no new evidence for organics, the factor representing the preservation of organics is assigned low.

\section{Habitability Index Computation Results}

[76] The method for computing the habitability index and its statistical uncertainty was described in section 3 through equations (1)-(6). Each of four probabilities, $P_{l w}, P_{e}, P_{c h}$, and $P_{b}$ are computed based on evaluating contributing factors. Table 2 shows the values for the four probabilities, the values assigned to the contributing factors, and the weighting of the factors for all landing sites visited. Table 3 summarizes each of the factors that contribute to the probabilities and provides the rationale for the values assigned for landing sites other than Phoenix. The reader desiring more detail about the factors and values assigned to them should refer to the discussion in Appendix A. Assigning values to the factors involves subjective choices and so we again emphasize that $H I$ is most useful as a relative assessment between landing sites based on what is known. Because the different missions did not make similar measurements, useful information is not available for many of the factors and in these cases the factors were not included in the calculation of the probability. In Tables 2 and 3 and Appendix A, this is signified by NA, or not applicable.

[77] Figure 10a plots results for the four computed probabilities for the five sites on Mars that have been visited by landers. Figure $10 \mathrm{~b}$ plots $H I$ and $H I_{\text {MEPAG. }} H I$ is largest for Phoenix at 0.43 , followed by Meridiani at 0.23 , Gusev at 0.22 , Pathfinder at 0.05 , Viking 1 at 0.01 , and Viking 2 at 0.07 . $H I_{\text {MEPAG }}$ is the product of only three probabilities $\left(P_{l w}, P_{e}, P_{c h}\right)$ and is therefore larger with 0.53 for Phoenix, 0.46 for Meridiani, 0.36 for Gusev, 0.10 for Pathfinder, 0.02 for VL1, and 0.10 for VL2.

[78] Differences that stand out in $H I$ values result primarily from the probabilities for the presence of liquid water, the presence of a benign environment, and the evaluation of the energy source. The presence of liquid water is the strongest discriminator between landing sites. The past presence of liquid water at Meridiani Planum is established by multiple lines of evidence, including morphological and mineralogical evidence, which is not matched at other sites. For this reason, Meridiani gets a score of $P_{l w}=1$, while Phoenix gets only $P_{l w}=0.58$. The Viking Lander 1 (VL 1) site gets the lowest score for $P_{l w}=0.04$ because no morphological (imaging) evidence for liquid water was observed at that site and none of the other observation types were acquired by Viking. VL 2 also gets a low score for this reason $\left(P_{l w}=0.17\right)$, but is somewhat higher than VL1 because some observations from Phoenix can be inferred to apply to the VL2 site since it is at a high northern latitude. The low score for $P_{l w}$ also means that the overall $H I$ for both Viking sites is low because the $H I$ is computed from the product of probabilities so if any individual probability is low, the $H I$ will also be low.

[79] $P_{e}$ is larger for Phoenix than the other sites because there is stronger evidence for a biological energy source at the Phoenix site compared to other sites. OM imaging of translucent sand-sized particles suggests that UV-shielded 
visible radiation may be a viable energy source, while the presence of perchlorate and the likely presence of ferrous iron suggest a potential redox couple. The other sites were assigned moderate values for $P_{e}$ based on presumed likelihood that biological energy sources are available, rather than any direct evidence.

[80] The Phoenix environment, with a well-buffered weakly alkaline soil, has the highest probability of a benign environment $\left(P_{b}=0.81\right)$ since a large variety of microbes can live at the measured $\mathrm{pH}$ of 7.8. It is possible that the Viking soils have a similar or identical $\mathrm{pH}$ [Quinn and Orenberg, 1993], but this is less certain than at the Phoenix site, given the absence of direct $\mathrm{pH}$ measurement. By contrast, the Meridiani site rates a lower score for this probability $\left(P_{b}=0.5\right)$ because the environmental stress associated with the low $\mathrm{pH}$ and high ionic strength inferred for the Meridiani site impacts its habitability [Squyres and Knoll, 2005; Tosca et al., 2008].

[81] Figure 10b graphically shows the results for computation of $H I$ at all landing sites. Given the 1-sigma error bars, it is possible that all sites are uninhabitable. Still, based on what is known and measured, Phoenix appears to have the highest $H I$. The computation also shows that only the Phoenix site exceeds the demanding $H I_{\text {MEPAG }}=50 \%$ requirement suggested by MEPAG to justify a follow-on life detection mission.

\section{Discussion}

[82] The Phoenix results provide a tantalizing glimpse into the potentially habitable NPR. The presence of pockets of nearly pure ice in the near subsurface was unexpected but is consistent with observations indicating that the water abundance in the high-altitude regions exceeds the pore space available to store vapor deposited ice in the soil [Boynton et al., 2002]. Geomorphological evidence also points to an ice-rich subsurface: a deposit $1-10 \mathrm{~m}$ thick mantles much of the Mars surface between 30 and $60^{\circ}$ latitude [Kreslavsky and Head, 2000, 2002; Kreslavsky et al., 2008] possibly resulting from snowfall deposited during high obliquity. HiRISE images of fresh impact craters [Byrne et al., 2009] show that near surface pure ice deposits are quite common in middle- to high-latitude regions of Mars. It is important to understand how the ice found by Phoenix was emplaced and models for the process include snowfall [Kreslavsky et al., 2008], segregated ice [Mellon et $a l ., 2009]$, and vapor deposition [Fisher, 2005]. Measurements of perchlorate concentration could allow differentiation among these models since the highly hygroscopic and soluble perchlorate would be concentrated by liquid water, but not by snow or vapor deposition. No variations of perchlorate concentrations were seen by Phoenix in the samples analyzed, but neither WCL nor TEGA analyzed samples obtained from in or near the pure ice so its perchlorate concentration is unknown. Samples were not obtained for these analyses because (1) the pure ice was at an awkward angle to be accessed by the robotic arm/ISAD device, (2) ice-rich soil excavated from the SW trench stuck to the scoop and TEGA screen and did not fall successfully into the TEGA instrument so the team felt that delivery of a pure ice sample was unlikely to succeed, (3) team consensus was that other samples had higher priority, and (4) a pure ice sample acquisition was planned for later in the mission but the mission ended before it was accomplished. Sample handling was unexpectedly difficult due to the stickiness of the material that is not fully understood. An important lesson learned from Phoenix is that future missions to sample icy materials on Mars must have sampling mechanisms that can overcome this stickiness, and their performance must be demonstrated in lab tests duplicating Martian conditions.

[83] It may surprise some that the computation of equations (1) and (2) suggest that the Phoenix landing site is more habitable than the sites visited by the Mars Exploration Rovers (Meridiani Planum and Gusev Crater) which both show strong evidence of liquid water activity in materials that are at least $4 \mathrm{Gyr}$ old. These materials were formed in the epoch often considered to be the most conducive to the origin and evolution of life. Phoenix receives a higher $H I$ score because of the lower probabilities of available energy and benign environmental conditions at the other two sites but it is difficult to compare a site where the habitable conditions are modern to one in which they are very ancient. On an ancient Mars, a thicker atmosphere may have provided more shielding against ionizing radiation, making the surface environment more habitable. In an environment where liquid water is common, perchlorate might not become concentrated enough to be a significant energy source subsurface. However, even if ancient life on Mars was common, finding unambiguous evidence of it will be more difficult than finding evidence of a modern biosphere, where the conditions may be harsher but the record is fresh. In the polar regions of Mars, there may be more than just a record of life; it may be possible to obtain and study living organisms representing a separate genesis from life on Earth.

[84] The semiquantitative approach used here for evaluation of the habitability of the Phoenix landing site could usefully be applied to estimating the probability of growth of terrestrial microbes that goes into setting planetary protection requirements. In fact, the "special regions" analysis by Beaty et al. [2006] considered many of the same factors that we have examined in analyzing the Phoenix observations. The formalism we present could help to further differentiate between sights and exploration methods requiring more or less stringent precautions to prevent contamination. Current planetary protection protocols require that only sterile tools touch ground ice. This was achieved on Phoenix by sterilizing the robotic arm components and housing them in a biobarrier that was removed on Mars. Based on present planetary protection guidelines, future missions to search for life will probably require sterilization of the complete spacecraft. The Viking Landers, the only example of spacecraft level sterilization performed to date, were sterilized by dry heat: an expensive procedure for current generation materials and electronics. Reasonable cost spacecraft sterilization methods are needed to enable missions that search for viable organisms, and funds are urgently needed to develop and certify these methods.

[85] Although Phoenix did not detect them, it is thermodynamically plausible that small pockets of highly concentrated perchlorate-rich brine form under current Martian conditions, either at the surface or at the soil-ice interface, where ice meets perchlorate rich particles on microscopic scales. These might produce the chemical and microscopic 

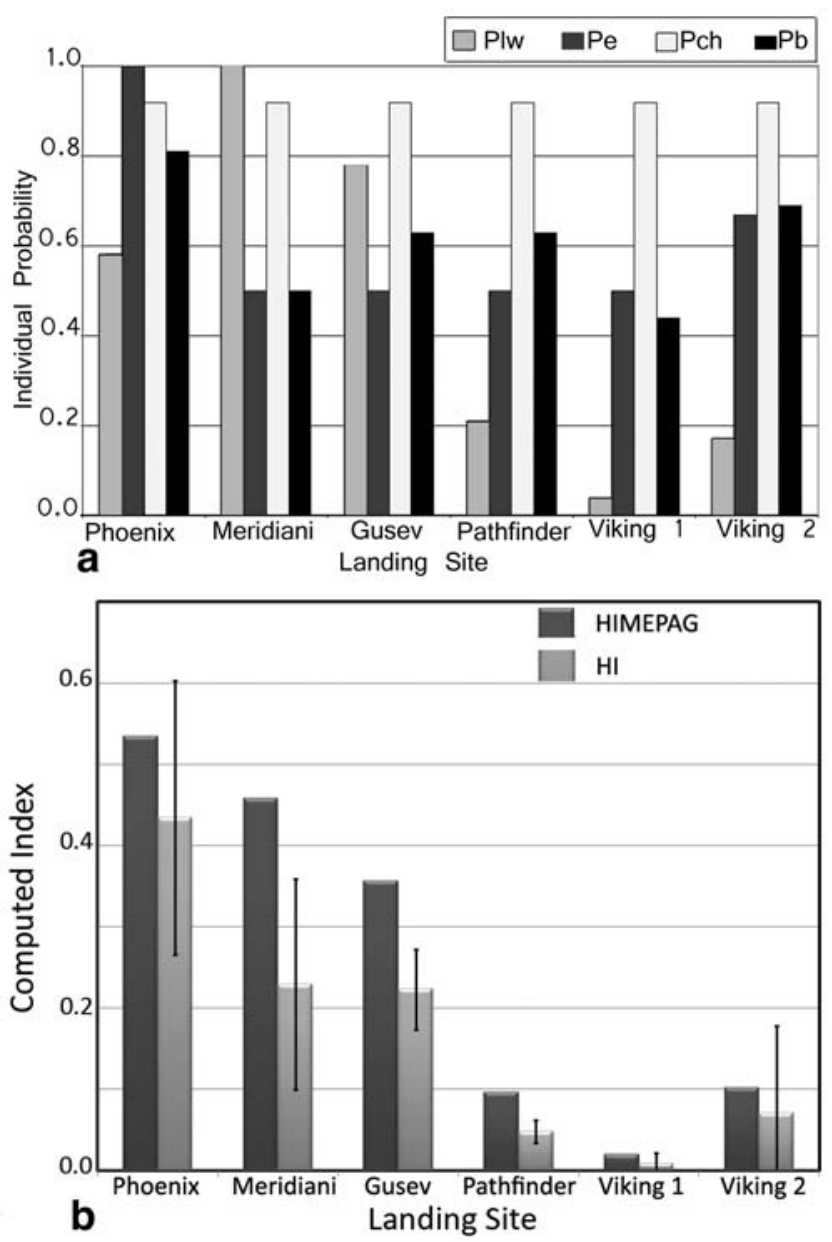

Figure 10. (a) Individual probabilities computed for each landing site for $P_{l w}$ (light gray), $P_{e}$ (dark gray), $P_{c h}$ (white), and $P_{b}$ (black). (b) Bar chart showing results of the habitability calculation. The dark gray bars are the computation of the $H I_{\text {MEPAG }}$. Light gray bars are computation of the $H I$ that includes the probability of a benign environment. Black lines represent statistical errors in the computation of $H I$.

evidence of liquid water alteration that Phoenix observed. However, these brines probably are not habitable at present. As discussed previously, the lowest temperature at which growth has been observed in terrestrial microbes is $253 \mathrm{~K}$ [Rivkina et al., 2000; Price and Sowers, 2004]. Even though current temperatures at the surface (Figure 7) exceed this value for a brief period each day during the summer, and ice is deposited on the surface in the coldest part of the night, it may already have sublimated when these temperatures are reached so water limits growth when temperature does not. Growth can only occur on the current surface or near subsurface of Mars if there are microhabitats where ice is allowed to warm but sublimation is prevented. We conclude, as did Jakosky et al. [2003], that the current environment of the NPR is near (but probably does not reach) the threshold of habitable conditions.

[86] The present-day temperatures in the ice table are far below those required for growth by terrestrial organisms (Figure 7). Zent [2008] modeled the depth and temperature of the ground ice as a function of changing insolation conditions and showed that, at obliquity greater than $40^{\circ}$, temperatures above $258 \mathrm{~K}$ exist in the icy subsurface for many tens of sols and the $258 \mathrm{~K}$ isotherm can penetrate to $75 \mathrm{~cm}$ depth during long periods of high obliquity. These durations exceed the doubling times for terrestrial psychrophiles [Rivkina et al., 2000] so it is plausible that microbial populations increase during these periods. Since films of unfrozen water are also available at these temperatures, the subsurface soils could support chemoautotrophic life that utilizes perchlorate as an energy source and $\mathrm{CO}_{2}$ as a carbon source. However, there are other periods when habitable conditions never occur in the ice table and, without maintenance metabolism, the near subsurface will be sterilized by ionizing radiation. According to Zent [2008, p.405], in the last $10 \mathrm{Myr}$, the longest continuous dormant period in the ice table is $7.6 \times 10^{5}$ years, and the worst periods occur in the last $5 \mathrm{Myr}$ where "although ice does reach temperatures warm enough for spores to germinate, repair damage, if possible, and grow, the temperatures may not be maintained for sufficient time to allow populations to rebound." Based on measuring spore inactivation by ionizing radiation, Kminek et al. [2003] predicted that the time required to reduce viable spore populations a million fold in the uppermost $10 \mathrm{~cm}$ is $7 \times 10^{4}$ years, and $6 \times 10^{5}$ years in the upper meter. Of course, even if the microbial spores have been killed by ionizing radiation, their remains would constitute an organic record of life. But a search for living organisms may require the capability to acquire and analyze samples from depths greater than $1 \mathrm{~m}$ to reach materials containing viable microbes that have not been sterilized by ionizing radiation.

[87] Based on the Phoenix results, a mission to search for life in the north polar region of Mars is warranted. This mission will need to improve on the Phoenix sampling system and should incorporate a drill and have the capability to recover and analyze samples from depths of greater than $1 \mathrm{~m}$. The most habitable recent conditions occurred during the last high obliquity period, $0.5-1 \times 10^{6}$ years ago and, since the time scales for surface sterilization are much shorter [Kminek et al., 2003], the material most likely to contain viable organisms is at least $1 \mathrm{~m}$ below the surface. During high insolation periods, snow may accumulate and more active hydrological cycling may result in more rapid resurfacing. Instruments needed for such a mission follow from lessons learned on Phoenix. The mission should be able to detect and analyze organic compounds, and detect variations in concentration of perchlorate ions. An instrument with similar capabilities to MECA/WCL would be appropriate for the latter assay. Because of the complications resulting from combustion of organics in the presence of strong oxidants, the preferred organic analysis method should not heat the samples. The MOMA instrument [Evans-Nguyen et al., 2008] selected for the ExoMars mission utilizes laser desorption instead of sample heating to volatilize organics and represents an appropriate technology. Another possible approach might utilize ultraviolet fluorescence spectroscopy, a promising method for characterizing organic compounds without requiring any sample processing [Bhartia et al., 2008]. Finally, life detection methods might use "lab on a chip" technology under development for a variety of rapid analyses. One promising 
life detection method utilizes antibody arrays that can detect a wide variety of biomarker compounds [Parro et al., 2005, 2008] from an assay using a single sample. The enzymes for perchlorate metabolism would be important to include in the assay.

[88] Microbial life is extraordinarily diverse on planet Earth, where some organisms are highly resistant to soluble elements and/or oxidizing environments that are toxic to others. Strong oxidants are inimical to many of the key organic processes in essential microbial metabolism, but terrestrial organisms have evolved an abundance of mechanisms to deal with such challenges. Perchlorate, in particular, in spite of its highly oxidized chlorine, is kinetically quite inert at ordinary planetary temperatures. However, the possible role of perchlorate precursors in the Martian environment deserves further study for their potential role in destroying organics or as potential biocides since several of the intermediates on the chemical genesis pathways from innocuous chlorides to perchlorate, such as hypochlorite, are among the more powerful microbial disinfectants known. Phoenix had no capability to detect these compounds.

[89] Although we were able to weigh the probability of key factors determining habitability, the margin of error is still significant owing to the small size of the available data sets. MEPAG set forth criteria for justifying a mission to search for life that $H I_{\mathrm{MEPAG}}$, or the combined probabilities of $P_{l w} \times P_{e} \times P_{c h}$, is greater than $50 \%$. Our results show that Phoenix meets this criteria but the absolute values of $H I$ are uncertain, so this conclusion is not robust and could be strengthened by future missions designed to further assess the presence of habitable conditions. The conclusion that the Phoenix site has highest probability for habitability of all landing sites visited is more robust. Phoenix, therefore took a step in the right direction but it will be important for future missions to other locations to measure parameters that indicate habitability to strengthen this conclusion. The profound significance of finding life on Mars warrants future missions to follow on the Phoenix discovery of a habitable environment for life.

\section{Appendix A: Assignment of Factors and Computed Probabilities for All Landing Sites}

[90] As discussed in the text, the computation of $H I$ is most meaningful for comparing the relative habitability of different landing sites. This section summarizes the values and rationale for the assignment for each factor that contributes to the computation of the four probabilities $P_{l w}, P_{e}$, $P_{c h}$, and $P_{b}$ for the landing sites at Meridiani Planum, Gusev Crater, and those visited by Mars Pathfinder and Viking Landers 1 and 2. Below we refer to these landing sites as Meridiani, Gusev, Pathfinder, VL1, and VL2.

[91] $P_{l w}$ is computed from four observational factors and three theoretical factors. To understand a result for $P_{l w}$, it is necessary to consider the values assigned to each of the factors so these are described next.

\section{A1. $F_{o b s 1}$ : Macroscopic Morphological Evidence of Liquid Water}

[92] This factor is assigned high for Meridiani because numerous reported features require liquid water for forma- tion including concretions, vugs and voids, and festoons [Squyres et al., 2004; Squyres and Knoll, 2005]. The factor is assigned high for Gusev Crater because orbital imaging of the area shows a crater lake breached by a channel [Cabrol et al., 2003]. For Pathfinder the factor is assigned low because morphological evidence suggests the area experienced a catastrophic flood [Golombek et al., 1999] but the duration of liquid water from such an event would be short. For VL 1 and 2 the factor is assigned null because no relevant morphological evidence was reported [Binder et al., 1977; Mutch et al., 1977].

\section{A2. $F_{o b s 2}$ : Microscopic Evidence for Liquid Water}

[93] The MER rovers each carried a microscopic imager. Numerous microscopic features diagnostic of diagenesis in an aqueous environment were identified at Meridiani so the factor is evaluated as high there. No such features were reported at Gusev so this factor is assigned null there. Since the other landers did not carry microscopic imaging, this factor was assigned NA for them.

\section{A3. $F_{o b s 3}$ : Evidence for Aqueous Mineralogy}

[94] Minerals that form in aqueous environments were identified at both Meridiani [Klingelhofer et al., 2004; Clark et al., 2005] and Gusev [Ming et al., 2006; Squyres et al., 2007] so this factor is rated high for each of them. No relevant observations that could identify aqueous mineralogy were performed at the other landing sites so the factors are NA for these sites.

\section{A4. $F_{o b s 4}$ : Evidence for Modern Thin Films of Water}

[95] TECP data was uniquely collected at the Phoenix site and for all other sites this factor is NA.

\section{A5. $F_{t h 1}$ : Presence of Liquid Water or Emplacement Mechanism for Water}

[96] Plausible mechanisms have been proposed for forming liquid water at each landing site, so this factor is high for all sites.

\section{A6. $F_{t h 2}$ : Thermodynamic Conditions Allowed Liquid Water to Exist in the Epoch When It Was Emplaced}

[97] For Meridiani and Gusev this factor is assigned high because the aqueous activity is believed to have taken place in the Noachian epoch when the climate was warmer and atmospheric pressure higher than at present. For the Pathfinder and VL 1 sites, this factor is assigned low because the aqueous activity occurred during the Hesperian epoch when the climate was probably similar to the modern conditions. The factor is high for the VL 2 site because thermodynamic conditions there are similar to the Phoenix site that is also evaluated as high.

\section{A7. $F_{t h 3}$ : Stability of Liquid Water Against Sublimation or Freezing}

[98] Liquid water may have been stable over long periods of time on ancient Mars so this factor is rated high for Meridiani and Gusev since these are the most ancient ter- 
rains. For all other landing sites the factor is rated medium, meaning that any liquid water formed in these environments is at best transient.

[99] When all the factors are taken into account, the highest scores for $P_{l w}$ goes to the Meridiani and Gusev sites since they have the strongest evidence, and the lowest scores go to the two Viking sites largely because no specific evidence for liquid water morphology was observed at these sites and the Vikings had no instrumentation for the other observational factors considered.

[100] $P_{e}$, the probability for energy, includes two factors, energy from sunlight $\left(F_{e 1}\right)$ and chemical energy $\left(F_{e 2}\right)$. Phoenix scores high for $F_{e 1}$ since there is evidence from microscopic imaging of translucent particles that can prevent damage to organisms from deep UV light. None of the other spacecraft have provided such evidence but the factor is assigned medium for all of them since there are many ways to hide from ultraviolet damage. Phoenix scored high for $\mathrm{F}_{\mathrm{e} 2}$ due to the detected presence of perchlorate. At the other landing sites this factor is assigned medium because, as a photochemical product, it is most likely to be globally distributed. However, the presence of perchlorate on early Mars is admittedly speculative.

[101] $P_{c h}$, the presence of the chemical constituents needed for life, is computed from factors associated with each of the elements $\mathrm{C}, \mathrm{H}, \mathrm{N}, \mathrm{O}, \mathrm{P}$, and $\mathrm{S}$. These factors are assigned the same numerical value for all landing sites because the atmosphere and globally distributed dust contain all the necessary nutrients.

[102] $P_{b}$, the probability of a benign environment, is calculated from four equally weighted factors, with values assigned as shown next.

\section{A8. $F_{T}$ : Temperature Is Consistent With Microbial Growth}

[103] For Meridiani this factor is high because abundant evidence for liquid water argues that temperatures must have been above the freezing point of water. The factor is assigned medium high for the Gusev site because there is less observed evidence for aqueous activity than at Meridiani. For Pathfinder and VL 1 sites, the factor is assigned medium because liquid water is brought to these sites during a flood, and temperatures high enough for microbial growth occur only in the summer season. The factor is assigned high at VL 2 because it is climatologically similar to the Phoenix site that was also assigned high.

\section{A9. $F_{a w}$ : Water Activity Allows Growth}

[104] The factor is assigned high for Phoenix based on the WCL measurements indicating low concentrations of soluble salts. For Meridiani, the factor is assigned low on the basis of arguments by Tosca et al. [2008] that water activity would inhibit growth in the acidic salty sediments there. For all other sites the factor is uncertain but the soil composition and inferred abundance of salts is remarkably similar between landing sites as inferred from X-ray Fluorescence and Alpha Proton X-ray data [Clark et al., 1977; Gellert et al., 2004] so medium is assigned because the soils are unlikely to be too salty to microbial growth.

\section{A10. $F_{\mathrm{pH}}$ : Conditions of $\mathrm{pH}$ Allow Growth}

[105] The factor is high for Phoenix since the measured $\mathrm{pH}$ was in an ideal range for growth. The factor is low for the Meridiani landing site because minerals present there imply a pH less than 4 [Squyres and Knoll, 2005]. While extremophile organisms can survive in low $\mathrm{pH}$ water, it is never the less a stressful condition inhibiting growth of most organisms, hence the low assignment. Reactions measured by the Viking biology experiments suggest that the Viking soils also have moderately alkaline $\mathrm{pH}$, so the factor is assigned medium high for both Viking sites. There is no relevant information for Pathfinder or Gusev sites so the factor is NA.

\section{A11. $F_{\text {org }}$ : Organics Preserved in the Environment}

[106] This factor relates to the probability that the environment preserves a record of life, which suggests both that the environment is benign for life and that biosignatures are preserved so searching for life might yield a positive outcome. The factor is low for Phoenix, rather than null, because organics might have been destroyed by combustion in the presence of oxygen from perchlorate in the samples [Ming et al., 2009]. For the Viking sites, the factor is scored null, based on the nondetection an organic compounds by those spacecraft. The other landers did not make relevant measurements so the factors there are NA.

[107] Acknowledgments. We gratefully acknowledge the contributions of the Phoenix Mars mission engineering and operations teams for a successful landing and effective landed spacecraft operations. Special thanks goes to the project scientist Leslie Tamppari for her encouragement and support in pursuing this topic. Lively discussion with the Biological Potential Science theme group members as well as other Phoenix science team members at numerous mission functions also contributed to the ideas presented in the paper. Finally, careful and extensive reviews by Brad Sutter and an anonymous reviewer helped to substantially strengthen the manuscript and we gratefully acknowledge their contribution.

\section{References}

Alexander, M. (1991), Introduction to Soil Microbiology, Krieger, Malabar, Fla.

Anderson, D. M., and A. R. Tice (1972), Predicting unfrozen water contents in frozen soils from surface area measurements, Highway Res. Record, 393, 12-18.

Arvidson, R. E., et al. (2008), Mars Exploration Program 2007 Phoenix landing site selection and characteristics, J. Geophys. Res., 113 E00A03, doi:10.1029/2007JE003021.

Arvidson, R. E., et al. (2009), Results from the Mars Phoenix Lander Robotic Arm experiment, J. Geophys. Res., 114, E00E02, doi:10.1029/ 2009JE003408.

Bandfield, J. L., et al. (2003), Spectroscopic identification of carbonate minerals in the Martian dust, Science, 301, 1084-1087, doi:10.1126/ science. 1088054

Bao, H. M., and B. H. Gu (2004), Natural perchlorate has a unique oxygen isotope signature, Environ. Sci. Technol., 38, 5073-5077, doi:10.1021/ es049516z.

Beaty, D. W., et al. (2006), Findings of the Mars special regions science analysis group, Astrobiology, 6, 677-732, doi:10.1089/ast.2006.6.677.

Bender, K. S., M. R. Rice, W. H. Fugate, J. D. Coates, and L. A. Achenbach (2004), Metabolic primers for the detection of (per)chlorate-reducing bacteria in the environment, Appl. Environ. Microbiol., 70, 5651-5658, doi:10.1128/AEM.70.9.5651-5658.2004

Besley, L. M., and G. A. Bottomley (1969), The water vapour equilibria over magnesium perchlorate hydrates, J. Chem. Thermodyn., 1, 13-19, doi:10.1016/0021-9614(69)90032-9.

Bevington, P. R. (1969), Data Reduction and Error Analysis for the Physical Sciences, McGraw-Hill, New York. 
Bhartia, R., et al. (2008), Classification of organic and biological materials with deep ultraviolet excitation, Appl. Spectrosc., 62, 1070-1077, doi:10.1366/000370208786049123.

Bibring, J. P., et al. (2007), Coupled ferric oxides and sulfates on the Martian surface, Science, 317, 1206-1210, doi:10.1126/science.1144174. Biemann, K. (2007), On the ability of the Viking gas chromatograph-mass spectrometer to detect organic matter, Proc. Natl. Acad. Sci. U. S. A., 104, 10,310-10,313, doi:10.1073/pnas.0703732104.

Biemann, K., J. Oro, P. Toulmin III, L. E. Orgel, A. O. Nier, D. M. Anderson, D. Flory, A. V. Diaz, D. R. Rushneck, and P. G. Simmonds (1977), The search for organic substances and inorganic volatile compounds in the surface of Mars, J. Geophys. Res., 82, 4641-4658, doi:10.1029/ JS082i028p04641.

Binder, A. B., et al. (1977), The geology of the Viking Lander 1 site, J. Geophys. Res., 82, 4439-4451, doi:10.1029/JS082i028p04439.

Bonitz, R. G., et al. (2008), NASA Mars 2007 Phoenix Lander Robotic Arm and Icy Soil Acquisition Device, J. Geophys. Res., 113, E00A01, doi:10.1029/2007JE003030.

Boynton, W. V., et al. (2002), Distribution of hydrogen in the near-surface of Mars: Evidence for sub-surface ice deposits, Science, 297, 81-85, doi:10.1126/science. 1073722 .

Boynton, W. V., et al. (2009), Evidence for calcium carbonate at the Mars Phoenix landing site, Science, 325, 61-64, doi:10.1126/science.1172768.

Bridges, J. C., D. C. Catling, J. M. Saxton, T. D. Swindle, I. C. Lyon, and M. M. Grady (2001), Alteration assemblages in Martian meteorites: Implications for near-surface processes, Space Sci. Rev., 96, 365-392, doi:10.1023/A:1011965826553.

Bruce, R. A., L. A. Achenbach, and J. D. Coates (1999), Reduction of (per) chlorate by a novel organism isolated from a paper mill waste, Environ. Microbiol., 1, 319-329, doi:10.1046/j.1462-2920.1999.00042.x.

Byrne, S., et al. (2009), Distribution of mid-latitude ground ice on Mars from new impact craters, Science, 325, 1674-1676, doi:10.1126/ science. 1175307.

Cabrol, N. A., et al. (2003), Exploring Gusev Crater with Spirit: Review of science objectives and testable hypotheses, J. Geophys. Res., 108(E12), 8076, doi:10.1029/2002JE002026.

Chapelle, F., K. O'Neill, P. M. Bradley, B. A. Methe, S. A. Clufo, L. L. Knobel, and D. R. Lovley (2002), A hydrogen-based subsurface microbial community dominated by methanogens, Nature, 415, 312 315, doi:10.1038/415312a.

Chaudhuri, S. K., J. G. Lack, and J. G. Coates (2001), Biogenic magnetite formation through anaerobic biooxidation of Fe(II), Appl. Environ. Microbiol., 67, 2844-2848, doi:10.1128/AEM.67.6.2844-2848.2001.

Clark, B. C., and D. van Hart (1981), The salts of Mars, Icarus, 45 370-378, doi:10.1016/0019-1035(81)90041-5.

Clark, B. C., et al. (1977), The Viking X-ray fluorescence experiment: Analytical methods and early results, J. Geophys. Res., 82, 4577-4594, doi:10.1029/JS082i028p04577.

Clark, B. C., et al. (2005), Chemistry and mineralogy of outcrops at Meridiani Planum, Earth Planet. Sci. Lett., 240, 73-94, doi:10.1016/ j.epsl.2005.09.040.

Coates, J. D., and L. A. Achenback (2004), Microbial perchlorate reduction: Rocket-fueled metabolism, Nat. Rev. Microbiol., 2, 569-580, doi: $10.1038 /$ nrmicro926.

Coates, J. D., et al. (1999), The ubiquity and diversity of dissimilatory (per) chlorate-reducing bacteria, Appl. Environ. Microbiol., 65, 5234-5241.

Coates, J. D., U. Michaelidou, S. M. O'Connor, R. A. Bruce, and L. A. Achenback (2000), The diverse microbiology of (per)chlorate reduction, in Perchlorate in the Environment, edited by E. T. Urbansky, pp. 257-270, Kluwer Acad., New York.

Cockell, C. S. (2001), The Martian and extraterretrial UV radiation environment Part II: Further considerations on materials and design criteria for artificial ecosystems, Acta Astronaut., 49(11), 631-640, doi:10.1016/ S0094-5765(01)00085-6.

Cockell, C. S., A. C. Schuerger, D. Billi, E. I. Friedmann, and C. Panitz (2005), Effects of a Simulated Martian UV Flux on the Cyanobacterium, Chroococcidiopsis sp. 029, Astrobiology, 5, 127-140, doi:10.1089/ ast.2005.5.127.

Dasgupta, P. K., P. K. Martinelango, W. A. Jackson, T. A. Anderson, K. Tian, R. W. Tock, and S. Rajagopalan (2005), The origin of naturally occurring perchlorate, Environ. Sci. Technol., 39, 1569-1575, doi: $10.1021 / \mathrm{es} 048612 \mathrm{x}$

Davis, N. T. (2001), Permafrost: A Guide to Frozen Ground in Transition, 351 pp. Univ. of Alaska Press, Fairbanks, Alaska.

Devore, J., and N. Farnum (1999), Applied Statistics for Engineers and Scientists, Duxbury, New York.

Douglas, S., and H. X. Yang (2002), Mineralogical biosignatures in evaporites: Presence of rosickyite in an endoevaporite community from
Death Valley, CA, Geology, 30, 1075-1078, doi:10.1130/0091-7613 (2002)030<1075:MBIEPO > 2.0.CO;2.

Douglas, S., W. J. Abbey, R. Mielke, P. G. Conrad, and I. Kanik (2008), Textural and mineralogical biosignatures in an unusual microbialite from Death Valley, California, Icarus, 193, 620-636, doi:10.1016/j.icarus. 2007.08.019.

Drake, F., and D. Sobel (1992), Is Anyone Out There? The Scientific Search for Extraterrestrial Intelligence, Souvenir Press, London.

Ericksen, G.E. (1981), Geology and origin of the Chilean nitrate deposits, U.S. Geol. Surv. Prof. Pap., 1188

Evans-Nguyen, T., L. Becker, V. Doroshenko, and R. J. Cotter (2008), Development of a low power, high mass range mass spectrometer for Mars surface analysis, Int. J. Mass Spectrom., 278, 170-177, doi:10.1016/j.ijms.2008.09.002.

Feldman, W. C., et al. (2002), Global distribution of neutrons from Mars: Results from Mars Odyssey, Science, 297, 75-78, doi:10.1126/science. 1073541.

Finegold, L. (1996), Molecular and biophysical aspects of adaptation of life to temperatures below the freezing point, Adv. Space Res., 18, 87-95, doi:10.1016/0273-1177(96)00003-8.

Fisher, D. A. (2005), A process to make massive ice in the Martian regolith using long-term diffusion and thermal cracking, Icarus, 179, 387-397, doi:10.1016/j.icarus.2005.07.024.

Fisk, M. R., and S. J. Giovannoni (1999), Source of nutrients and energy for a deep biosphere on Mars, J. Geophys. Res., 104, 11,805-11,815, doi:10.1029/1999JE900010.

Flemming, C. A., F. G. Ferris, T. J. Beveridge, and G. W. Bailey (1990), Remobilization of toxic heavy metals adsorbed to bacterial wall-clay composites, Appl. Environ. Microbiol., 56, 3191-3203.

Friedmann, E. I. (1982), Endolithic Microorganisms in the Antarctic Cold Desert, Science, 215, 1045-1053, doi:10.1126/science.215.4536.1045

Gal, H., Z. Ronen, N. Weisbrod, O. Dahan, and R. Nativ (2008), Perchlorate biodegradation in contaminated soils and the deep unsaturated zone, Soil Biol. Biochem., 40, 1751-1757, doi:10.1016/j.soilbio.2008.02.015.

Gellert, R., et al. (2004), Chemistry of rocks and soils in Gusev Crater from the alpha particle X-ray spectrometer, Science, 305, 829-832, doi: $10.1126 /$ science. 1099913

Gendrin, A., et al. (2005), Sulfates in Martian layered terrains, the OMEGA/Mars Express view, Science, 307, 1587-1591, doi:10.1126/ science. 1109087.

Golden, D. C., D.W. Ming, B. Sutter, R.V. Morris, W.V. Boynton, M.H. Hecht, and S.P. Kounaves (2009), Sulfur mineralogy at the Mars Phoenix landing site, Lunar Planet. Sci., XL, Abstract 2319.

Golombek, M. P., et al. (1999), Overview of the Mars Pathfinder mission: Launch through landing, surface operations, data sets, and science results, J. Geophys. Res., 104, 8523-8553, doi:10.1029/98JE02554.

Grant, W. D. (2004), Life at low water activity, Philos. Trans. R. Soc London B, 359, 1249-1267, doi:10.1098/rstb.2004.1502.

Haberle, R. M., J. R. Murphy, and J. Schaeffer (2003), Orbital change experiments with a Mars general circulation model, Icarus, 161, 66-89, doi:10.1016/S0019-1035(02)00017-9.

Hall, K., M. Guglielmin, and A. Strini (2008), Weathering of granite in Antarctica: I. Light penetration into rock and implications for rock weathering and endolithic communities, Earth Surf. Processes Landforms, 33 295-307, doi:10.1002/esp.1618.

Hanley, J., V. F. Chevrier, and T. S. Altheide (2009), Low temperature aqueous perchlorate solutions on the surface of Mars, Lunar Planet. Sci., XL, Abstract 1380 .

Hecht, M. H., et al. (2008), Microscopy capabilities of the Microscopy, Electrochemistry, and Conductivity Analyzer, J. Geophys. Res., 113, E00A22, doi:10.1029/2008JE003077.

Hecht, M. H., et al. (2009), Soluble chemistry of Martian soil: Findings from the Phoenix Mars Lander, Science, 324, 64-67.

Jakosky, B., K. Nealson, C. Bakermans, R. Ley, and M. Mellon (2003), Subfreezing activity of microorganisms and the potential habitability of Mars' polar regions, Astrobiology, 3, 34-350, doi:10.1089/ 153110703769016433

Junge, K., H. Eicken, and J. W. Deming (2004), Bacterial Activity at -2 to $-20^{\circ} \mathrm{C}$ in Arctic wintertime sea ice, Appl. Environ. Microbiol., 70 550-557, doi:10.1128/AEM.70.1.550-557.2004.

Kahn, R. (1990), Ice haze, snow, and the Mars water cycle, J. Geophys Res., 95, 14,677-14,693, doi:10.1029/JB095iB09p14677.

Keller, H. U., et al. (2008), Phoenix Robotic Arm Camera, J. Geophys Res., 113, E00A17, doi:10.1029/2007JE003044.

Klein, H. P. (1978), The Viking biological experiments on Mars, Icarus, 34, 666-674, doi:10.1016/0019-1035(78)90053-2.

Klingelhofer, G., et al. (2004), Jarosite and hematite at Meridiani Planum from Opportunity's Mossbauer Spectrometer, Science, 306, 1740-1745, doi:10.1126/science. 1104653 
Kminek, G., J. L. Bada, K. Pogliano, and J. F. Ward (2003), Radiationdependent limit for the viability of bacterial spores in halite fluid inclusions and on Mars, Radiat. Res., 159, 722-729, doi:10.1667/00337587(2003)159[0722:RLFTVO]2.0.CO;2.

Kounaves, S. P., et al. (2009), The MECA Wet Chemistry Laboratory on the 2007 Phoenix Mars Scout Lander, J. Geophys. Res., 114, E00A19, doi:10.1029/2008JE003084.

Kounaves, S. P., et al. (2010a), Wet Chemistry experiments on the 2007 Phoenix Mars Scout Lander mission: Data analysis and results, J. Geophys. Res., 115, E00E10, doi:10.1029/2009JE003424.

Kounaves, S. P., et al. (2010b), Soluble sulfate in the Martian soil at the Phoenix landing site, Geophys. Res. Lett., 37, L09201, doi:10.1029/ 2010GL042613.

Kreslavsky, M. A., and J. W. Head (2000), Kilometer-scale roughness of Mars: Results from MOLA data analysis, J. Geophys. Res., 105 26,695-26,711, doi:10.1029/2000JE001259.

Kreslavsky, M. A., and J. W. Head (2002), Mars: Nature and evolution of young latitude-dependent water-ice-rich mantle, Geophys. Res. Lett., 29(15), 1719, doi:10.1029/2002GL015392.

Kreslavsky, M. A., J. W. Head, and D. R. Marchant (2008), Periods of active permafrost layer formation during the geological history of Mars Implications for circum-polar and mid-latitude surface processes, Planet. Space Sci., 56, 289-302, doi:10.1016/j.pss.2006.02.010.

Krinsley, D. H. (1973), Atlas of Quartz Surface Sand Textures, Cambridge Univ. Press, Cambridge, U. K.

Lack, J. G., S. K. Chaudhuri, R. Chakraborty, L. A. Achenbach, and J. D. Coates (2002), Anaeroic biooxidation of Fe(II) by Decholorosoma suillum, Microb. Ecol., 43, 424-431, doi:10.1007/s00248-001-1061-1.

Langevin, Y., F. Poulet, J. P. Bibring, and B. Gondet (2005), Sulfates in the north polar region of Mars detected by OMEGA/MarsExpress, Science, 307, 1584-1586, doi:10.1126/science.1109091.

Laskar, J., A. C. M. Correia, M. Gastineau, F. Joutel, B. Levrard, and P. Robutel (2004), Long term evolution and chaotic diffusion of the insolation quantities of Mars, Icarus, 170, 343-364, doi:10.1016/j.icarus. 2004.04.005.

Malmqvist, A., T. Welander, E. Moore, A. Ternstrom, G. Molin, and I. Stenstrom (1994), Ideonella dechloratans gen. nov., sp. nov., a new bacterium capable of growing anaerobically with chlorate as an electron acceptor, Syst. Appl. Microbiol., 17, 58-64

Manning, C. V., C. P. McKay, and K. J. Zahnle (2008), The nitrogen cycle on Mars: Impact decomposition of near-surface nitrates as a source for a nitrogen steady state, Icarus, 197, 60-64, doi:10.1016/j.icarus 2008.04.015.

Marshall, J. R. (1987), Clastic Particles: Scanning Electron Microscopy and Shape Analysis of Sedimentary and Volcanic Clasts, 346 pp., Van Nostrand Reinhold, New York.

Mautner, M., and S. Sinaj (2002), Water extractable and exchangeable phosphate in Martian and carbonaceous chondrite meteorites and in planetary soil analogs, Geochim. Cosmochim. Acta, 66, 3161-3174, doi:10.1016/S0016-7037(02)00910-9.

McSween, H. Y., Jr., et al. (1999), Chemical, multispectral, and textural constraints on the composition and origin of rocks at the Mars Pathfinder landing site, J. Geophys. Res., 104, 8679-8715, doi:10.1029/98JE02551.

Mellon, M. T., et al. (2009), Ground ice at the Phoenix landing site: Stability state and origin, J. Geophys. Res., 114, E00E07, doi:10.1029/ 2009JE003417.

Michaelidou, U., L. A. Achenbach, and J. D. Coates (2000), Isolation and characterization of two novel per(chlorate)-reducing bacteria from swine waste lagoons, in Perchlorate in the Environment, edited by E. T. Urbansky, pp. 271-283, Kluwer Acad., New York.

Michalski, G., J. K. Bohlke, and M. Thiemens (2004), Long term atmospheric deposition as the source of nitrate and other salts in the Atacama Desert, Chile: New evidence from mass-independent oxygen isotopic compositions, Geochim. Cosmochim. Acta, 68, 4023-4038, doi:10.1016/ j.gca.2004.04.009.

Miller, J. P., and B. E. Logan (2000), Sustained perchlorate degradation in an autotrophic, gas-phase, packed-bed bioreactor, Environ. Sci. Technol. 34, 3018-3022, doi:10.1021/es991155d.

Ming, D. W., et al. (2006), Geochemical and mineralogical indicators for aqueous processes in the Columbia Hills of Gusev Crater, Mars, J. Geophys. Res., 111, E02S12, doi:10.1029/2005JE002560.

Ming, D. W., et al. (2008), Mars 2007 Phoenix Scout mission Organic Free Blank: Method to distinguish Mars organics from terrestrial organics, J. Geophys. Res., 113, E00A21, doi:10.1029/2007JE003061.

Ming, D.W., P. D. Archer Jr., H. Imanaka, M. A. Smith, D. W. Ming, W. V. Boynton, and P. H. Smith (2009), UV photolysis of mellitic acid: A possible organic at the Mars Phoenix landing site, Lunar Planet. Sci., XL, Abstract 2077.
Mitrofanov, I. G., et al. (2002), Maps of subsurface hydrogen from the High Energy Neutron Detector, Mars Odyssey, Science, 297, 78-81, doi:10.1126/science. 1073616 .

Moores, J. E., M. T. Lemmon, P. H. Smith, L. Komguem, and J. A. Whiteway (2010), Atmospheric dynamics at the Phoenix landing site as seen by the Surface Stereo Imager, J. Geophys. Res., 115, E00E08, doi:10.1029/2009JE003409.

Morris, R. V., et al. (2004), Mineralogy at Gusev Crater from the Mössbauer spectrometer on the Spirit rover, Science, 305, 833-836, doi:10.1126/science. 1100020

Mutch, T. A., et al. (1977), The geology of the Viking lander 2 site, J. Geophys. Res., 82, 4452-4467, doi:10.1029/JS082i028p04452.

Navarro-Gonzalez, R., et al. (2006), The limitations on organic detection in Mars-like soils by thermal volatilization-gas chromatography-MS and their implications for the Viking results, Proc. Natl. Acad. Sci. U. S. A., 103, 16,089-16,094, doi:10.1073/pnas.0604210103.

Nienow, J. A., C. P. McKay, and E. I. Friedmann (1988), The cryptoendolithic microbial environment in the Ross desert of Antarctica: Light in the photosynthetically active region, Microb. Ecol., 16, 271-289, doi:10.1007/BF02011700.

Parnell, J., P. Lee, C. S. Cockell, and G. R. Osinski (2004), Microbial colonization in impact-generated hydrothermal sulfate deposits: Haughton impact structure and implications for sulfates on Mars, Int. J. Astrobiol., 3, 247-256, doi:10.1017/S1473550404001995.

Parro, V., et al. (2005), Instrument development to search for biomarkers on Mars: Terrestrial acidophile, iron-powered chemolithoautotrophic communities as model systems, Planet. Space Sci., 53, 729-737, doi:10.1016/j.pss.2005.02.003.

Parro, V., et al. (2008), SOLID2: An antibody array-based life detector instrument in a Mars Drilling Simulation Experiment (MARTE), Astrobiology, 8(5), 987-999, doi:10.1089/ast.2007.0126.

Pestova, O. N., L. A. Myund, M. K. Khripun, and A. V. Prigaro (2005), Polythermal study of the systems $\mathrm{M}\left(\mathrm{ClO}_{4}\right)_{2}-\mathrm{H}_{2} \mathrm{O}\left(\mathrm{M}^{2+}=\mathrm{Mg}^{2+}, \mathrm{Ca}^{2+}\right.$ $\left.\mathrm{Sr}^{2+}, \mathrm{Ba}^{2+}\right)$, Russ. J. Appl. Chem., 78, 409-413, doi:10.1007/s11167005-0306-Z.

Potts, M. (1994), Dessication tolerance of prokaryotes, Microbiol. Rev., 58 , $755-805$.

Price, B. P., and T. Sowers (2004), Temperature dependence of metabolic rates for microbial growth, maintenance, and survival, Proc. Natl. Acad. Sci. U. S. A., 101, 4631-4636, doi:10.1073/pnas.0400522101.

Quinn, R., and J. Orenberg (1993), Simulations of the Viking gas-exchange experiment using palagonite and Fe-rich Montmorillonite as terrestrial analogs: Implications for the surface-composition of Mars, Geochim. Cosmochim. Acta, 57, 4611-4618, doi:10.1016/0016-7037(93)90186-Z. Rao, M. N., S. R. Sutton, D. S. McKay, and G. Dreibus (2005), Clues to Martian brines based on halogens in salts from nakhlites and MER samples, J. Geophys. Res., 110, E12S06, doi:10.1029/2005JE002470.

Rennó, N. O., et al. (2009), Possible physical and thermodynamical evidence for liquid water at the Phoenix landing site, J. Geophys. Res., 114, E00E03, doi:10.1029/2009JE003362.

Richardson, M. I., and M. A. Michna (2005), Long-term evolution of transient liquid water on Mars, J. Geophys. Res., 110, E03003, doi:10.1029/ 2004JE002367.

Rikken, G., A. Kroon, and C. Van Ginkel (1996), Transformation of (per) chlorate into chloride by a newly isolated bacterium: Reduction and dismutation, Appl. Microbiol. Biotechnol., 45, 420-426, doi:10.1007/ s002530050707.

Rivkina, E. M., E. I. Freidmann, C. P. McKay, and D. A. Gilchinsky (2000), Metabolic activity of permafrost bacteria below the freezing point, Appl. Environ. Microbiol., 66, 3230-3233, doi:10.1128/ AEM.66.8.3230-3233.2000.

Romanenko, V. I., V. N. Korenkov, and S. I. Kuznetsov (1976), Bacterial decomposition of ammonium perchlorate, Mikrobiologiva, 45, 204-209.

Schuerger, A. C., R. L. Mancinelli, R. G. Kern, L. J. Rothschild, and C. P. McKay (2003), Survival of endospores of Bacillus subtilis on spacecraft surfaces under simulated Martian environments: Implications for the forward contamination of Mars, Icarus, 165, 253-276, doi:10.1016/S00191035(03)00200-8

Schulte, M., D. Blake, T. Hoehler, and T. McCollom (2006), Serpentinization and its implications for life on the early Earth and Mars, Astrobiology, 6, 364-376, doi:10.1089/ast.2006.6.364

Schultze-Lam, D. S., and T. J. Beveridge (1994), Physicochemical characteristics of the mineral-forming S-layer from the cyanobacterium, Synechococcus GL24, Can. J. Microbiol., 40, 216-223, doi:10.1139/m94-035.

Seinfeld, J. H., and S. N. Pandis (2006), Atmospheric Chemistry and Physics. From Air Pollution to Climate Change, 2nd ed., John Wiley, New York. Smith, P. E. (2002), The Phoenix Scout mission, Lunar Planet. Sci. $X X X I V$, Abstract 1855 
Smith, P. E., et al. (2008), Introduction to special section on the Phoenix Mission: Landing site characterization experiments, mission overviews, and expected science, J. Geophys. Res., 113, E00A18, doi:10.1029/ 2008JE003083.

Smith, P. E., et al. (2009), Water at the Phoenix landing site, Science, 325, 58-61, doi:10.1126/science.1172339.

Squyres, S. W., and A. Knoll (2005), Sedimentary rocks at Meridiani Planum: Origin, diagenesis, and implications for life on Mars, Earth Planet. Sci. Lett., 240, 1-10, doi:10.1016/j.eps1.2005.09.038.

Squyres, S. W., et al. (2004), Opportunity rover's Athena science investigation at Meridiani Planum, Mars, Science, 306, 1698-1703, doi:10.1126/science. 1106171

Squyres, S. W., et al. (2007), Pyroclastic activity at Home Plate in Gusev Crater, Mars, Science, 316, 738, doi:10.1126/science.1139045.

Stepanyuk, V. V., G. F. Smirnova, T. M. Klyushnikova, N. I. Kanyuk, L. P. Pachenko, T. M. Nogina, and V. I. Prima (1992), New species of the Acinetobacter genus Acinetobacter thermotoleranticus sp. nov, Mikrobiologiya, 61, 347-356.

Stevens, T. O., and J. P. McKinley (1995), Lithoautotrophic microbial ecosystems in deep basalt aquifers, Science, 270, 450-455, doi:10.1126/ science. 270.5235 .450 .

Stumm, W., and J. J. Morgan (1995), Aquatic Chemistry: Chemical Rates and Equilibria in Natural Waters, John Wiley, New York.

Sykulska, H., W. T. Pike, and S. Vijendran (2009), Microscopy analysis of the salt content of soil and dust at the Phoenix landing site, Lunar Planet. Sci., XL, Abstract 2366.

Tamppari, L. K., M. D. Smith, D. S. Bass, and A. S. Hale (2007), Water-ice clouds and dust in the north polar region of Mars using MGS TES data, Planet. Space Sci., 56, 227-245.

Tanaka, K., J. Skinner, and T. Hare (2005), Geologic map of the northern plains of Mars, U.S. Geol. Surv. Misc. Invest. Map, 2888.

Tosca, N. J., A. H. Knoll, and S. M. McLennan (2008), Water activity and the challenge for life on early Mars, Science, 320, 1204-1207, doi:10.1126/science. 1155432 .

Wallace, W., T. Ward, A. Breen, and H. Attaway (1996), Identification of an anaerobic bacterium which reduces perchlorate and chlorate as Wolinella succinogenes, J. Ind. Microbiol., 16, 68-72, doi:10.1007/ BF01569924.

Watanabe, K., and M. Mizoguchi (2002), Amount of unfrozen water in frozen porous media saturated with solution, Cold Reg. Sci. Technol., 34(2), 103-110, doi:10.1016/S0165-232X(01)00063-5.

Wentworth, S. J., E. K. Gibson, M. A. Velbel, and D. S. McKay (2005), Antarctic dry valleys and indigenous weathering in Mars meteorites: Implications for water and life on Mars, Icarus, 174, 383-395, doi:10.1016 j.icarus.2004.08.026.
Whiteway, J., M. Daly, A. Carswell, T. Duck, C. Dickinson, L. Komguem, and C. Cook (2008), Lidar on the Phoenix mission to Mars, J. Geophys. Res., 113, E00A08, doi:10.1029/2007JE003002.

Whiteway, J. A., et al. (2009), Mars water ice clouds and precipitation, Science, 325, 68-70, doi:10.1126/science.1172344.

Whitten, B. A., and M. Potts (1999), The Ecology of Cyanobacteria: Their Diversity in Time and Space, 669 pp., Kluwer Acad., Boston.

Zent, A. (2008), A historical search for habitable ice at the Phoenix landing site, Icarus, 196, 385-408, doi:10.1016/j.icarus.2007.12.028.

Zent, A. P., M. H. Hecht, D. R. Cobos, G. S. Campbell, C. S. Campbell, G. Cardell, M. C. Foote, S. E. Wood, and M. Mehta (2009), Thermal and Electrical Conductivity Probe (TECP) for Phoenix, J. Geophys. Res., 114, E00A27, doi:10.1029/2007JE003052.

Zent, A. P., M. H. Hecht, D. R. Cobos, S. E. Wood, T. L. Hudson, S. M. Milkovich, L. P. DeFlores, and M. T. Mellon (2010), Initia results from the thermal and electrical conductivity probe (TECP) on Phoenix, J. Geophys. Res., 115, E00E14, doi:10.1029/2009JE003420.

P. D. Archer Jr. and P. H. Smith, Lunar and Planetary Laboratory, University of Arizona, Tucson, AZ 85721, USA. (darcher@1pl.arizona. edu; psmith@1pl.arizona.edu)

D. C. Catling, Department of Earth and Space Sciences, University of Washington, Box 351310, Seattle, WA 98195, USA. (davidc@u. washington.edu)

B. Clark, Space Science Institute, 4750 Walnut St., Boulder, CO 80301, USA. (bclark@SpaceScience.org)

S. Douglas, Jet Propulsion Laboratory, MS 183-301, 4800 Oak Grove

Dr., Pasadena, CA 91109-8099, USA. (susanne.douglas@jpl.nasa.gov)

S. P. Kounaves, Department of Chemistry, Tufts University, Medford, MA 02155, USA. (samuel.kounaves@tufts.edu)

M. T. Lemmon, Department of Atmospheric Sciences, Texas A\&M University, College Station, TX 77843, USA. (lemmon@physics.tamu.edu)

J. R. Marshall and R. Quinn, SETI Institute, 515 N. Whisman Rd. Mountain View, CA 94043, USA. (jmarshall@seti.org; Richard.c.quinn@ nasa.gov)

N. Renno, Department of Atmospheric, Oceanic, and Space Sciences, University of Michigan, Ann Arbor, MI 48103, USA. (nrenno@umich.edu) C. R. Stoker and A. Zent, NASA Ames Research Center, MS 245-3, Moffett Field, CA 94035, USA. (Carol.r.stoker@nasa.gov; aaron.zent@ nasa.gov)

S. M.M. Young, Department of Chemistry, University of New Hampshire, Durham, NH 03824, USA. (SuzanneMMYoung13@aol.com) 